\title{
Interface Reactions Responsible for Run-Out in Active Brazing: Part 2
}

\author{
The microstructural characteristics of braze joints made between the \\ Kovar ${ }^{\mathrm{TM}}$ base materials and Ag-xAl filler metals were examined
}

BY P. T. VIANCO, C. A. WALKER, D. De SMET, A. KILGO, B. M. McKENZIE, AND R. L. GRANT

\begin{abstract}
This study examined the microstructural characteristics of braze joints made between two Kovar ${ }^{\mathrm{TM}}$ base materials using the filler metals, Ag-xAl, having $\mathrm{x}=0,2,5$, and $10 \mathrm{wt}-\%$ Al additions. Brazing processes used temperatures of $965^{\circ}$ and $995^{\circ} \mathrm{C}\left(1769^{\circ}\right.$ and $\left.1823^{\circ} \mathrm{F}\right)$ and brazing times of 5 and $20 \mathrm{~min}$. All brazing was performed under high vacuum. The present study built upon the findings of Part 1 to identify the first-principles mechanism(s) responsible for run-out and to develop a mitigation strategy to prevent this anomaly. Run-out occurs when A) capillary flow is present, and B) the Al concentration in the filler metal is equal to, or greater than, 2 wt-\%. The latter condition corresponds to the $\mathrm{Al}$ content exceeding 25 at.-\% in the reaction layer at the filler metal interface. Reaction layer cracking was observed only with the Ag-10Al filler metal and was attributed to its lower ductility that prevented the relaxation of residual stresses. The reaction layer thickness increased with $\mathrm{Al}$ concentration in the Ag-xAl filler metal, but was not significantly affected by the brazing process parameters. The layer thickness, like the reaction layer compositions, were not dependent upon the thermally activated rate kinetics. Rather, the chemical potential (driving force) was determined by the $\mathrm{Al}$ content. Minimizing $\mathrm{Al}$ content in the filler metal will mitigate run-out.
\end{abstract}

\section{KEYWORDS}

- Run-Out • Active Brazing • Metal-to-Ceramic

\section{Introduction}

\section{Run-Out in Ag-Cu-Zr Active Braze Joints}

Run-out is an undesirable phenomenon in braze joints that is often attributed to an excessive quantity of filler metal. However, another scenario for run-out was observed during the development of a braze joint between alumina ceramic and Kovar ${ }^{\mathrm{TM}}$ base material (29.0Ni-17.0Co-0.30Mn$0.20 \mathrm{Si}-0.02 \mathrm{C}$-bal.Fe) using the active filler metal, $97 \mathrm{Ag}-1 \mathrm{Cu}-$ $2 \mathrm{Zr}$ (wt-\%, abbreviated Ag-Cu-Zr) (Refs. 1, 2). Run-out was attributed to a localized instability in the wetting and spreading behavior of the molten filler metal. Microanalysis confirmed that $\mathrm{Al}$, which is released by the reductionoxidation (redox) reaction between $\mathrm{Zr}$ and alumina, caused the run-out event when it diffused to, and then reacted with, the Kovar ${ }^{\mathrm{TM}}$ base material. The early studies determined that the driving force for run-out was on par with the surface energy of the molten filler metal. Therefore, braze joint geometry has a significant role in the run-out event as it introduces surface tension effects.

A follow-on study documented the reaction between $\mathrm{Al}$ and $\operatorname{Kovar}^{\mathrm{TM}}$ base material. The Part 1 investigation examined the wetting-and-spreading behavior of binary Ag-xAl ( $\mathrm{x}$ $=0,2,5$, and $10 \mathrm{wt}-\%$,) filler metals on $\mathrm{Kovar}^{\mathrm{TM}}$ base material using the sessile drop configuration (Ref. 3). Particular attention was given to the $(\mathrm{Fe}, \mathrm{Ni}, \mathrm{Co})_{\mathrm{x}} \mathrm{Al}_{\mathrm{y}}$ reaction layer that developed at the $\mathrm{Ag}$-xAl/Kovar ${ }^{\mathrm{TM}}$ base material interface. $\mathrm{Al}-$ though typical run-out lobes (Fig. 1) were not observed, general wetting and spreading behavior increased significantly when the $\mathrm{Al}$ content in the filler metal was greater than $2-5 \mathrm{wt}-\%$. This trend correlated to $\mathrm{Al}$ concentrations in the $(\mathrm{Fe}, \mathrm{Ni}, \mathrm{Co})_{\mathrm{x}} \mathrm{Al}_{\mathrm{y}}$ reaction layer that exceeded $30-35$ at.- $\%$. The Part 1 findings also established a general insensitivity of wetting and spreading as well as reaction layer composition to the brazing temperature and time. This trend was similar to findings for the alumina/Ag-Cu- $\mathrm{Zr} / \mathrm{Kovar}^{\mathrm{TM}}$ braze joints evaluated in Ref. 1.

The analysis in Ref. 1 indicated that run-out was sensitive to the geometry of the braze joint. The run-out lobes were not observed in the sessile drop configuration used in Part 1 (Ref. 3). This Part 2 study replaced the sessile drop configuration with a braze joint geometry between two Kovar ${ }^{\mathrm{TM}}$ base materials. This configuration introduced the effects capillary forces into the wetting and spreading behavior vis-à-vis the run-out of Ag-xAl filler metals ( $x=2,5$, and $10 \mathrm{wt}-\%)$. 


\section{Alumina}

\section{Alumina}

\section{Ag-Cu-Zr run-out}

Fig. 1 - Photograph shows run-out by the Ag-Cu-Zr active braze alloy used to join two alumina parts to a Kovar'm flange.

\section{Experimental Procedures}

\section{Base Material}

Braze joint test samples were constructed using two annular flanges of Kovar ${ }^{\mathrm{TM}}$ base material (29.0Ni-17.0Co$0.30 \mathrm{Mn}-0.20 \mathrm{Si}-0.02 \mathrm{C}$-bal.Fe). Each flange had an outside diameter of $25.4 \mathrm{~mm}$ (1.00 in.); an inside diameter of $6.4 \mathrm{~mm}$ (0.25 in.); and thickness of $0.51 \mathrm{~mm}$ (0.020 in.).

\section{Filler Metal}

The starting filler metal was 100Ag. Aluminum additions were made by evaporating $\mathrm{Al}$ onto one surface of the filler metal preform. The Al layer thicknesses resulted in concentrations of 2, 5, and $10 \mathrm{wt}-\%$ that matched those used in the Part 1 study. Each preform had the same annular ring configuration as the Kovar $^{\mathrm{TM}}$ flanges and a thickness of $0.051 \mathrm{~mm}$ (0.002 in.).

\section{Brazing Process}

Duplicate test samples were fabricated under one of the four combinations of the brazing temperatures, $965^{\circ}$ $\left(1769^{\circ}\right)$ or $995^{\circ} \mathrm{C}\left(1823^{\circ} \mathrm{F}\right)$, and brazing times, 5 or $20 \mathrm{~min}$. Brazing was performed under a high vacuum of $10^{-7}$ torr to prevent oxidation of the Al coating. Silver evaporation was minimal from the braze joint.

The braze joint was formed by placing two filler metal preforms between two Kovar ${ }^{\mathrm{TM}}$ flanges. The preforms were placed so that the Al-coated sides faced one another along the centerline of the clearance. This geometry required the Al to cross the molten filler metal to react with the Kovar ${ }^{\mathrm{TM}}$ base material, which duplicates the conditions during the fabrication of an actual metal/ceramic braze joint.

\section{Data Analysis}

The data analysis began with a visual inspection of the test samples for run-out lobes similar to that in Fig. 1. The findings were documented in photographs.

The microanalysis was performed on a metallographic cross section made across the diameter of one of the duplicate test specimens. The energy-dispersive $\mathrm{x}$-ray (EDX) analysis technique provided a qualitative assessment of elemental distributions within the braze joints. The accelerating voltage was 20 $\mathrm{keV}$. Quantitative compositions were determined of the reaction layers and filler metal by electron probe microanalysis (EPMA). The latter technique used an accelerating voltage of $15 \mathrm{keV}$ and a beam current of $20 \mathrm{nA}$. Data acquisition was performed in $0.5-\mu \mathrm{m}$ steps. The absolute spatial resolution limit was $\pm 0.75 \mu \mathrm{m}$, or an area of $1.5 \mu \mathrm{m}$ diameter based upon sampling volume effects under this acceleration voltage. Reaction layer concentrations are presented in atomic percent (at.-\%) while filler metal concentrations are described in weight percent (wt-\%). The concentration resolutions are \pm 0.5 at. $\%$ and $\pm 0.1 \mathrm{wt}-\%$ for the elemental species. The traces were performed across the entire braze joint, beginning and ending in the two Kovar $^{\mathrm{TM}}$ base materials.

The EPMA results were described according to filler metal composition, Ag-xAl, where $\mathrm{x}$ was equal to $0,2,5$, and $10 \mathrm{wt}-\%$. The analysis began by investigating the composition of the interface reaction layer phase(s). The reaction layer boundaries were identified by $\mathrm{Al}$ concentrations that had dropped to less than one atomic percent (resolution range calculated from \pm 0.5 at.- $\%$ ) at the interfaces with the filler metal and Kovar ${ }^{\mathrm{TM}}$ base material. Based upon the sessile drop data in Part 1, it was anticipated that multiple phases could develop in the interface reaction layer. Therefore, compositions were determined at three locations in the layer. Phase designations were given as low-Al near the Ko$\operatorname{var}^{\mathrm{TM}}$ base material; medium-Al at the center of the reaction layer; and high-Al near the filler metal. The compositional analyses were performed using three traces at both reaction layers for a total of six data per specimen. A designated composition was represented by the mean and an error term of plus-or-minus one standard deviation.

The EPMA technique was also used to measure the concentrations of $\mathrm{Al}, \mathrm{Fe}, \mathrm{Ni}$, and $\mathrm{Co}$ in the filler metal. The filler metal composition was determined at the center of the clearance.

The last analysis was that of the reaction layer thicknesses. Each thickness was determined by placing two lines along the respective edges of the reaction layer. The distance between the lines represented the nominal thickness. The error term was $\pm 0.1 \mu \mathrm{m}$ for this procedure, based upon the repeatability of multiple measurements. 


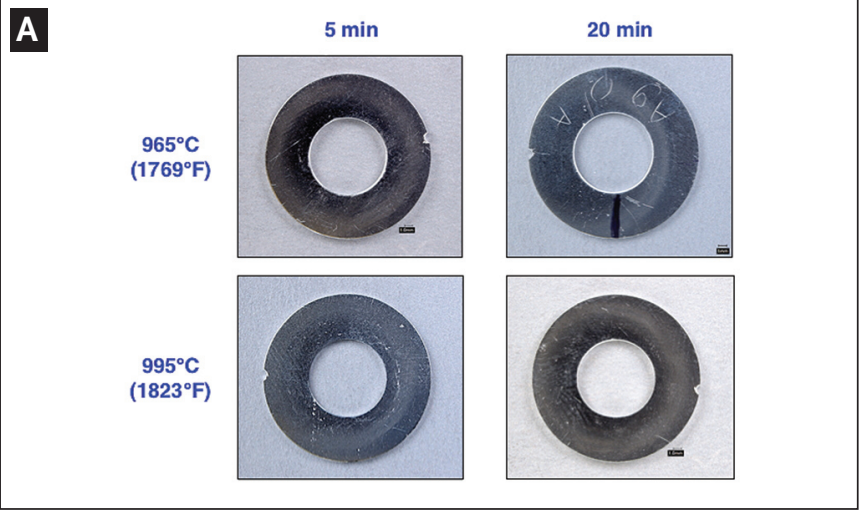

C

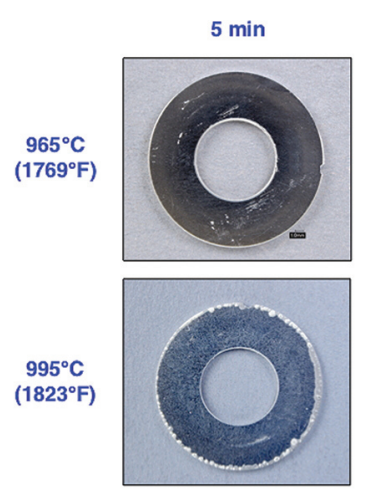

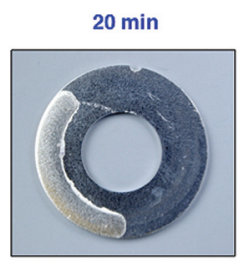

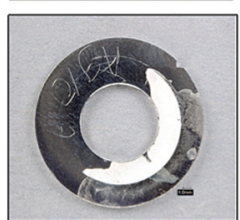

B
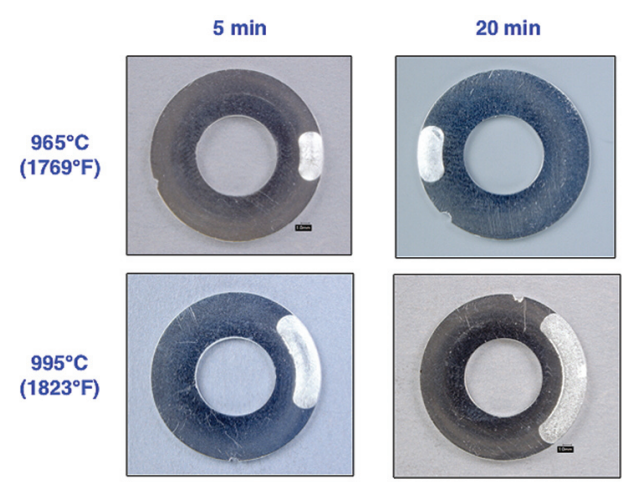

D
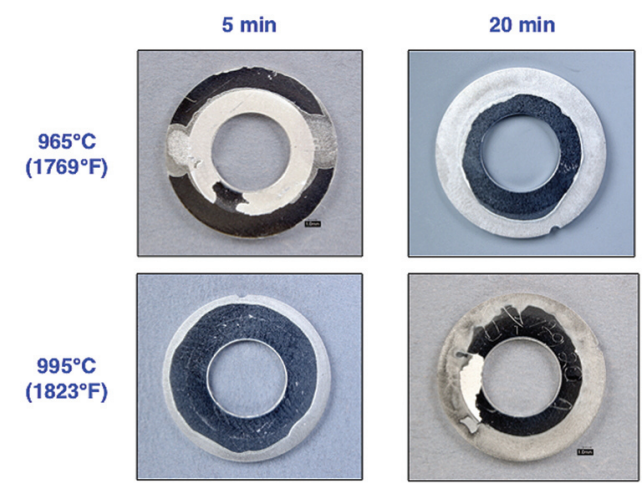

Fig. 2 - Optical photographs show the extent of run-out as a function of brazing conditions and filler metal composition: A -0 wt-\% Al; B - 2 wt-\% Al; C - 5 wt-\% Al; D - 10 wt-\% Al.

\section{Results}

\section{Visual Inspection for Run-Out}

Run-out exhibited limited variation between the duplicate test specimens. A top-down photograph is provided in Fig. 2 of one sample per Al concentration, brazing temperature, and brazing time. The photographs in Fig. 2A show that run-out was absent from joints made with the Ag-OAl filler metal, regardless of brazing temperature and time duration.

Those samples brazed with the Ag-2Al filler metal are shown in Fig. 2B. The braze joints exhibited a run-out lobe geometry. The run-out increased with brazing temperatures and to a lesser degree with brazing time. A comparison of Fig. $2 \mathrm{~A}$ and $\mathrm{B}$ confirmed the requirement for $\mathrm{Al}$ to be present for run-out to take place.

Figure $2 \mathrm{C}$ shows the specimens representing the $\mathrm{Ag}-5 \mathrm{Al}$ filler metal. Run-out was very limited for the sample brazed for $965^{\circ} \mathrm{C}\left(1769^{\circ} \mathrm{F}\right)$ and $5 \mathrm{~min}$. But it became more extensive across the sample edges and faces under the other three brazing conditions. In fact, this run-out exceeded the extent typically observed with metal-to-ceramic braze joints (e.g., Fig. 1).

Lastly, the Ag-10Al filler metal experienced very widespread run-out under all brazing conditions as shown in Fig. 2D. The run-out was too extensive to discern a trend as a function of brazing temperature or time.

The findings presented in Fig. 2 were compared to the absence of run-out by the sessile drop samples in Part 1. Recall that the latter specimens exhibited accelerated wetting and spreading behavior in the range of $2-5 \mathrm{wt}-\% \mathrm{Al}$ concentration. This behavior correlates to the expanded run-out over the same concentration range in Fig. 2. Also, this comparison indicates the lobe geometry is a consequence of the joint configuration.

\section{Microanalysis of Braze Joint Cross Sections}

The Part 1 study correlated the wetting and spreading behavior to the reaction layer composition. The same approach is used in the present study. The Part 1 analysis did not measure the reaction layer thickness. The layer thickness was documented in Part 2 to A) determine thickness versus brazing parameters and B) identify a correlation, if any, between reaction layer thickness and composition. The physical metallurgies will be categorized according to each Ag-xAl composition.

\section{Ag-0Al Filler Metal}

These test specimens did not exhibit run-out - Fig. 2A. The Ag-0Al cross section is shown in Fig. 3 for the sample fabricated at $965^{\circ} \mathrm{C}\left(1769^{\circ} \mathrm{F}\right)$ and $5 \mathrm{~min}$. Delamination or cracks were not observed along either interface. A reaction layer was not identified at the $\mathrm{Ag}-0 \mathrm{Al} / \mathrm{Kovar}^{\mathrm{TM}}$ interface nor were additional phases observed in the filler metal. This same microstructure was replicated for the other brazing conditions.

The EPMA was performed on the sample brazed at $995^{\circ} \mathrm{C}$ $\left(1823^{\circ} \mathrm{F}\right)$ for $5 \mathrm{~min}$ and was deemed representative of the 


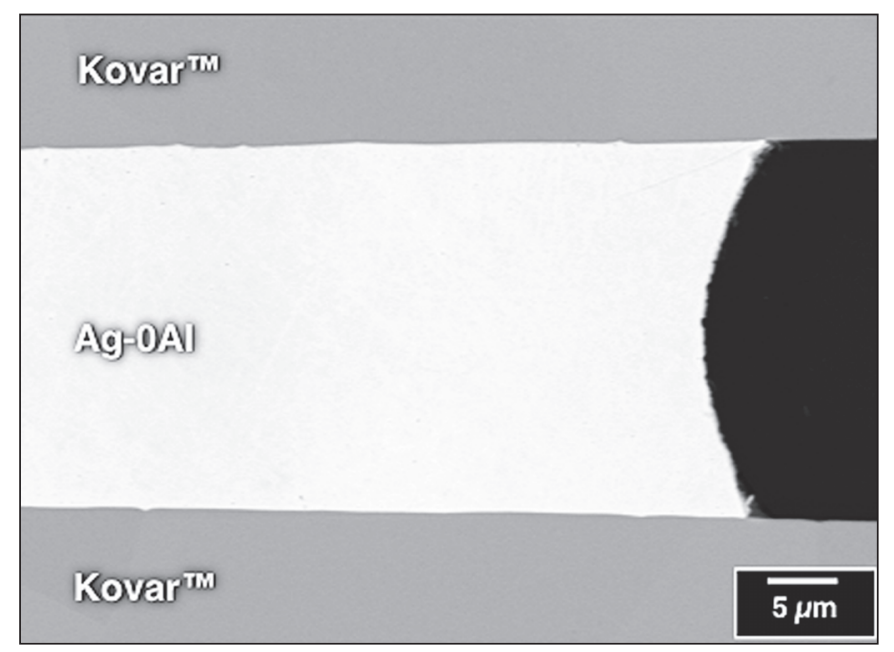

Fig. 3 - SEM photograph shows the Ag-OAl braze joint fabricated at $965^{\circ} \mathrm{C}\left(1769^{\circ} \mathrm{F}\right)$ and $5 \mathrm{~min}$.

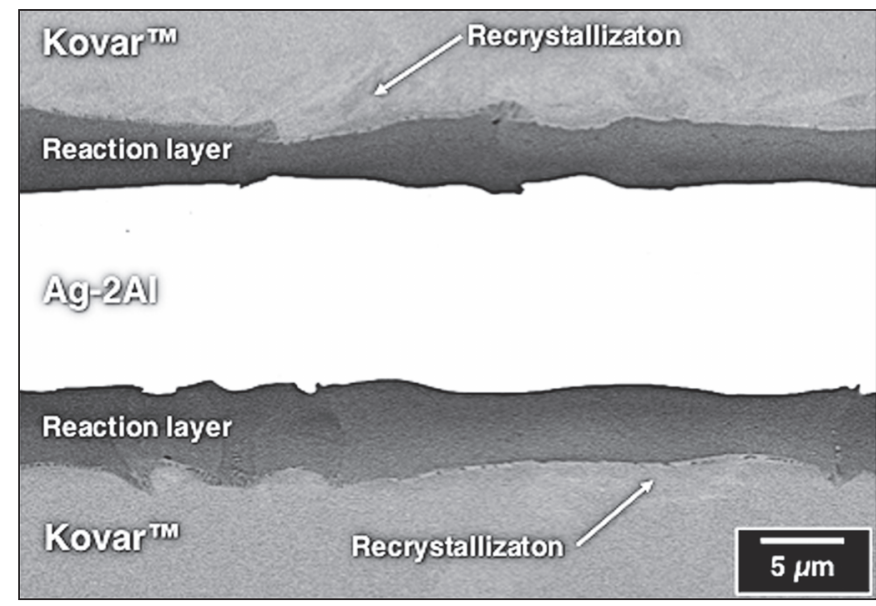

Fig. 5 - SEM photograph shows the Ag-2Al braze joint made at $965^{\circ} \mathrm{C}\left(1769^{\circ} \mathrm{F}\right)$ and $5 \mathrm{~min}$.

other samples, based on the initial EDX analysis. The representative trace is shown in Fig. 4. A reaction layer was not discernable at either interface to within the spatial resolution limit $( \pm 0.75 \mu \mathrm{m})$.

The concentrations of $\mathrm{Fe}, \mathrm{Ni}$, and Co were measured in the center of the clearance. Those values (wt-\%) were Fe, $0.4 \pm 0.1 ; \mathrm{Ni}, 0.2 \pm 0.1$; and $\mathrm{Co}, 0.2 \pm 0.1$. The fact the error terms were equivalent to the absolute error indicates the elemental concentration did not vary outside of the measurement error. The value for $\mathrm{Al}$ was well below $\pm 0.1 \mathrm{wt}-\%$ detection limit. The $\mathrm{Fe}, \mathrm{Ni}$, and $\mathrm{Co}$ signals were nearly an order of magnitude above the background level. The binary alloy phase diagrams for Ag-Co, Ag-Fe, and Ag-Ni indicate solubility limits of a few tenths of a weight percent for $\mathrm{Co}, \mathrm{Fe}$, and $\mathrm{Ni}$, respectively, at the brazing conditions (Ref. 4). Because phase separation was not observed in the $\mathrm{Ag}-\mathrm{OAl}$ alloy, these elements existed as slightly supersaturated solutions at room temperature.

The Fe, Ni, and Co traces exhibited gradients over approximately two microns into the Ag-0Al filler metal from either interface. The "smearing" artifact during metallographic sample preparation was investigated as a potential

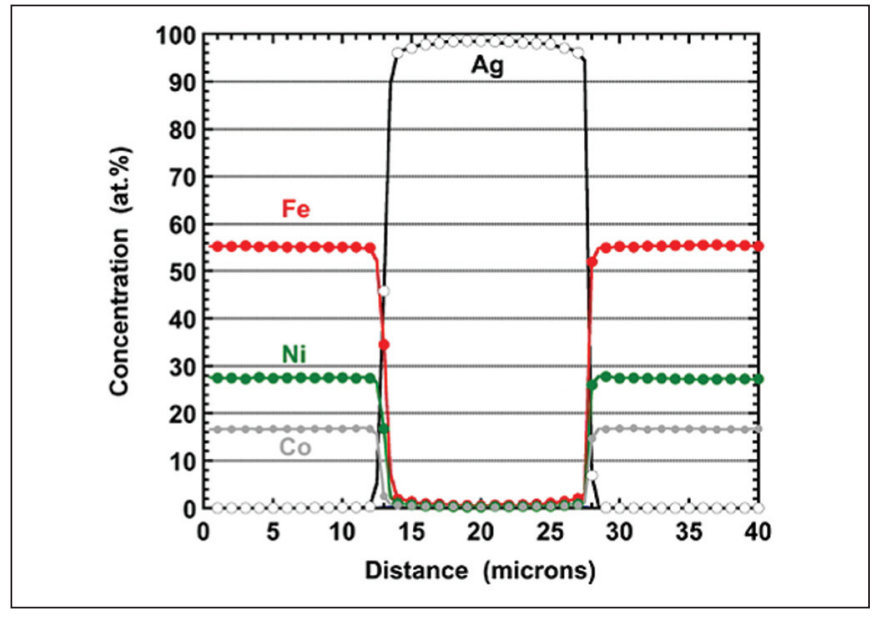

Fig. 4 - Plot shows the EPMA trace made across the joint clearance of the braze joint made with the Ag-OAl filler metal. The brazing conditions were $995^{\circ} \mathrm{C}\left(1823^{\circ} \mathrm{F}\right)$ and $5 \mathrm{~min}$.

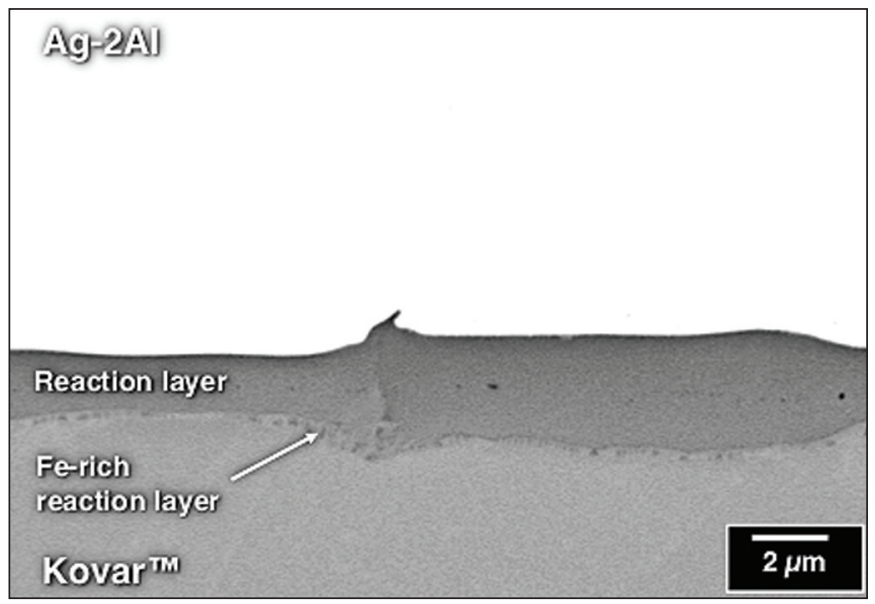

Fig. 6 - SEM photograph shows the interface microstructure of the Ag-2Al filler metal brazed at $965^{\circ} \mathrm{C}\left(1769^{\circ} \mathrm{F}\right)$ for $5 \mathrm{~min}$.

source of these gradients. The assumption was made that mechanically removed, or smeared, particles would have the same composition as the Kovar ${ }^{\mathrm{TM}}$ base material. The elemental fraction, $\mathrm{Z} /(\mathrm{Fe}+\mathrm{Ni}+\mathrm{Co})$, where $\mathrm{Z}$ represents $\mathrm{Fe}, \mathrm{Ni}$, or $\mathrm{Co}$, was calculated, based upon their respective concentrations in the center region of the Ag-OAl filler metal. Those elemental fractions varied significantly, having the following ranges: $\mathrm{Fe}, 0.43-0.53 ; \mathrm{Ni}, 0.25-0.33$; and $\mathrm{Co}, 0.16-0.25$. By comparison, the Kovar $^{\mathrm{TM}}$ base material exhibited fractions of $\mathrm{Fe}, 0.54 ; \mathrm{Ni}, 0.28$; and $\mathrm{Co}, 0.17$, which should vary across the EPMA traces under a smearing scenario. Therefore, smearing was an unlikely source of either the interface gradients or $\mathrm{Fe}, \mathrm{Ni}$, and Co concentrations in the filler metal.

\section{Ag-2Al Filler Metal}

The Ag-2Al samples exhibited run-out that increased slightly as a function of brazing temperature and time Fig. 2B. Reaction layers were observed at both interfaces. Figure 5 shows the reaction layer that formed after brazing at $965^{\circ} \mathrm{C}\left(1769^{\circ} \mathrm{F}\right)$ for $5 \mathrm{~min}$. The reaction layer thickness was $2.6 \pm 0.6 \mu \mathrm{m}$, based on ten measurements. Neither the 

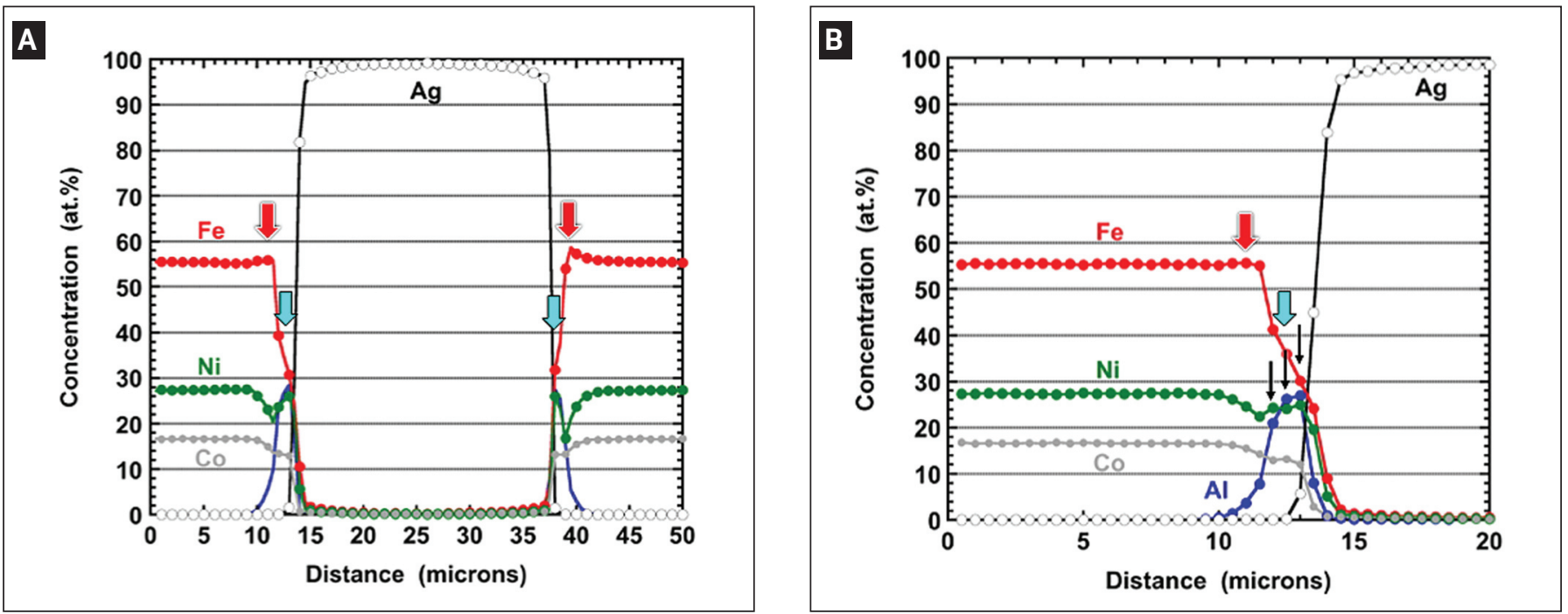

Fig. 7-A - EPMA trace was taken across the $\mathrm{Ag}-2 \mathrm{Al}$ braze joint made at $965^{\circ} \mathrm{C}\left(1769^{\circ} \mathrm{F}\right)$ and 5 min. The cyan arrows point to the reaction layers and the red arrows, the Fe-rich reaction layer; B - enlarged segment of the EPMA trace shows the left-hand side reaction layer. The black arrows indicate the measurement points of the low-, medium-, and high-Al concentrations (left to right).

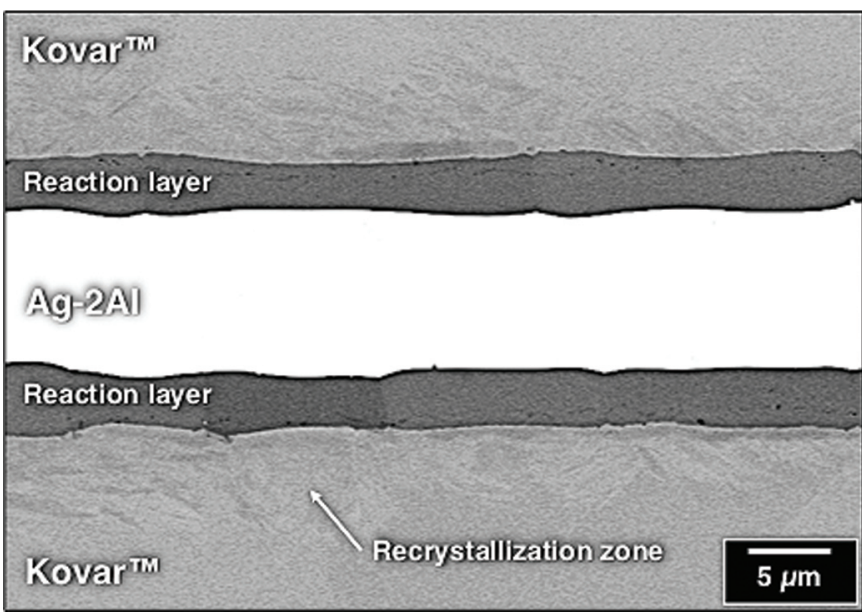

Fig. 8 - SEM photograph shows the Ag-2Al braze joint fabricated at $995^{\circ} \mathrm{C}\left(1823^{\circ} \mathrm{F}\right)$ and $20 \mathrm{~min}$.

reaction layer thickness or its microstructure changed as a function of joint clearance. Recrystallization was observed in the Kovar ${ }^{\mathrm{TM}}$ base material.

Shown in Fig. 6 is a higher magnification, SEM photograph of the reaction layer. The layer appeared to have a single phase. Cracks were not present in the reaction layer. The Fe-rich reaction layer was visible next to the Kovar ${ }^{\mathrm{TM}}$ base material. At this particular location, recrystallization was not observed in the latter.

The EPMA trace is shown in Fig. 7A that spanned the entire joint. The cyan arrows indicate the reaction layers, and the red arrows indicate the Fe-rich layer. The trace was amplified in Fig. 7B to show the left-hand side reaction layer. The Fe-rich layer was accompanied by a minimum in the $\mathrm{Ni}$ signal and a sharp drop-off of the Co signal. The interface reaction layers showed gradients by the $\mathrm{Fe}, \mathrm{Ni}, \mathrm{Co}$, and $\mathrm{Al}$ concentrations. Three compositions were determined at the black arrows in Fig. 7, which represented the low-, medium-, and high-Al concentration points within the reaction layer.
The corresponding compositions are listed as follows:

- Low-Al composition: (Fe, Ni, Co $)_{79 \pm 8} \mathrm{Al}_{21 \pm 3} \approx(\mathrm{Fe}, \mathrm{Ni}$, Co) ${ }_{4} \mathrm{Al}$

- Medium-Al composition: (Fe, Ni, Co $)_{75 \pm 4} \mathrm{Al}_{25 \pm 2} \approx(\mathrm{Fe}, \mathrm{Ni}$, (o) ${ }_{3} \mathrm{Al}$

- High-Al composition: (Fe, Ni, Co $)_{73 \pm 6} \mathrm{Al}_{27 \pm 2} \approx(\mathrm{Fe}, \mathrm{Ni}$, Co) ${ }_{3} \mathrm{Al}$

Only the low- and high-Al compositions were statistically different from one another. A single composition of ( $\mathrm{Fe}, \mathrm{Ni}$, Co $)_{74 \pm 4} \mathrm{Al}_{26 \pm 2} \approx(\mathrm{Fe}, \mathrm{Ni}, \mathrm{Co})_{3} \mathrm{Al}$ was calculated to represent the entire layer. Because the Part 1 study indicated the $\mathrm{Al}$ content of the reaction layers controlled the run-out phenomenon, the individual concentrations of $\mathrm{Fe}, \mathrm{Ni}$, and Co components were not recorded and instead were combined together as a single constituent (Ref. 3 ).

The $\mathrm{Fe}, \mathrm{Ni}, \mathrm{Co}$, and $\mathrm{Al}$ concentrations were determined in the Ag-2Al filler metal to be (wt-\%): Fe, $0.2 \pm 0.1 ; \mathrm{Ni}, 0.1 \pm 0.1$; Co, 0.1 \pm 0.1 ; and $\mathrm{Al}, 0.1 \pm 0.1$. These values were similar to those recorded in the $\mathrm{Ag}-\mathrm{OAl}$ filler metal to within experimental error. The $\mathrm{Al}$ concentration indicates nearly all of the original $2.0 \mathrm{wt}-\% \mathrm{Al}$ content was consumed by formation of the reaction layers.

Braze joints were also examined for the Ag-2Al filler metal and the process parameters of $965^{\circ} \mathrm{C}\left(1769^{\circ} \mathrm{F}\right)$ for 20 min. A statistically significant trend could not be established between reaction layer thickness and joint clearance. The reaction layer thickness was $3.2 \pm 0.8 \mu \mathrm{m}$, which is statistically similar to that measured after the five-minute brazing time. The SEM and EDX data indicated a single-phase reaction layer and only isolated regions of recrystallization in the nearby Kovar $^{\mathrm{TM}}$ base material. Cracks were not observed in the layers. The EPMA was not performed on these specimens; the assumption was made that the reaction layer composition was similar to that in Fig. 7.

The braze joint that was fabricated at $995^{\circ} \mathrm{C}\left(1823^{\circ} \mathrm{F}\right)$ for 5 min was examined. The joint clearance of $1.5 \pm 1.0 \mu \mathrm{m}$ was considerably thinner than for the previous two cases. The SEM images and EDX analysis indicated a single phase in 
A

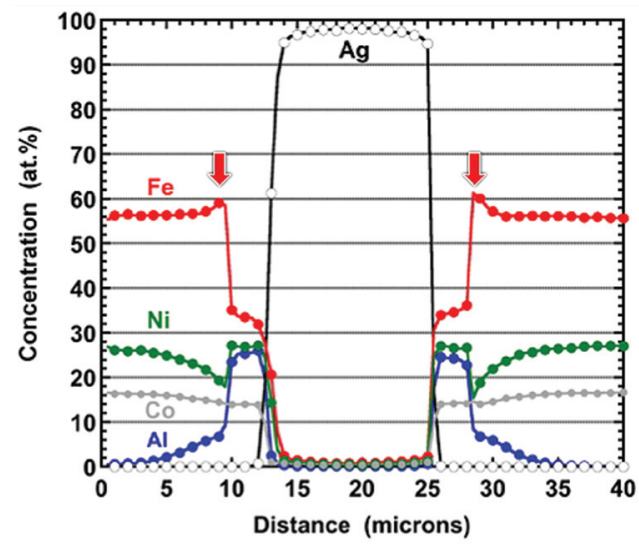

B

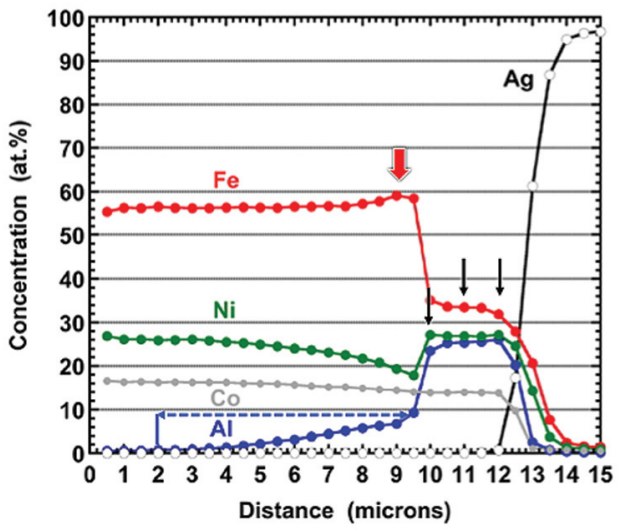

Fig. 9-A - EPMA trace was obtained from the braze joint fabricated with the Ag-2Al filler metal and brazing conditions of $995^{\circ} \mathrm{C}$ $\left(1823^{\circ} \mathrm{F}\right)$ and $20 \mathrm{~min}$. The red arrows indicate the Fe-rich reaction layer; B - enlarged EPMA trace focuses on the left-hand reaction. The blue dashed arrow identifies a recrystallization zone. The black arrows indicate the measurement points of the low-, medium-, and high-Al concentrations (left to right).

the reaction layers and cracking was absent.

The SEM photograph in Fig. 8 shows the Ag-2Al braze joint that was fabricated at $995^{\circ} \mathrm{C}\left(1823^{\circ} \mathrm{F}\right)$ and $20 \mathrm{~min}$. The reaction layer thickness was $2.7 \pm 0.5 \mu \mathrm{m}$ and did not show a significant dependence on joint clearance. The reaction layer gray tones suggested a single-phase composition. Cracks were absent from the layers. The EDX confirmed that a heightened Al signal accompanied the recrystallized zone in the adjoining Kovar $^{\mathrm{TM}}$ base material.

Figure 9A shows an EPMA trace taken across the Ag-2Al joint $\left[995^{\circ} \mathrm{C}\left(1823^{\circ} \mathrm{F}\right), 20 \mathrm{~min}\right]$. The reaction layers are readily identified by the $\mathrm{Al}$ peaks at the interfaces. The Fe-rich layer developed at the Kovar ${ }^{\mathrm{TM}} /$ reaction layer interface (red arrows), which was accompanied by a minimum in the $\mathrm{Ni}$ trace and a gradual decline of the Co signal.

Figure 9B is an enlarged view at the left-hand side interface. The $\mathrm{Ni}$ and $\mathrm{Co}$ concentrations are relatively constant across the reaction layer. The Al trace exhibited a slightly increasing gradient toward the filler metal that was matched by a decreasing $\mathrm{Fe}$ signal ${ }^{1}$.

The EPMA confirmed the negligible Al gradient in the reaction layer by the concentrations measured at the three black arrows in Fig. 9B:

- Low-Al composition: $(\mathrm{Fe}, \mathrm{Ni}, \mathrm{Co})_{76 \pm 2} \mathrm{Al}_{24 \pm 1} \approx(\mathrm{Fe}, \mathrm{Ni}$, Co) ${ }_{3} \mathrm{Al}$

- Medium-Al composition: $(\mathrm{Fe}, \mathrm{Ni}, \mathrm{Co})_{75 \pm 2} \mathrm{Al}_{24.8 \pm 0.8} \approx(\mathrm{Fe}$, $\mathrm{Ni}, \mathrm{Co})_{3} \mathrm{Al}$

- High-Al composition: $(\mathrm{Fe}, \mathrm{Ni}, \mathrm{Co})_{75 \pm 2} \mathrm{Al}_{25 \pm 1} \approx(\mathrm{Fe}, \mathrm{Ni}$, Co) ${ }_{3} \mathrm{Al}$

The concentrations were not statistically different so a nominal composition was calculated to represent the entire reaction layer: $(\mathrm{Fe}, \mathrm{Ni}, \mathrm{Co})_{75 \pm 2} \mathrm{Al}_{25 \pm 1} \approx(\mathrm{Fe}, \mathrm{Ni}, \mathrm{Co})_{3} \mathrm{Al}$. Whether three compositions or a single nominal composition, the $\mathrm{Al}$ concentrations were similar to those of the $\mathrm{Ag}$ $2 \mathrm{Al}$ reaction layers formed at $965^{\circ} \mathrm{C}\left(1769^{\circ} \mathrm{F}\right)$ for $5 \mathrm{~min}$. However, the smaller error terms, here, indicate that a more consistent composition was produced by the more severe

1. These compositional variations were below the SEM and EDX detection limits, which explains the earlier assertion that the reaction layer had a single phase and the value of the EPMA.

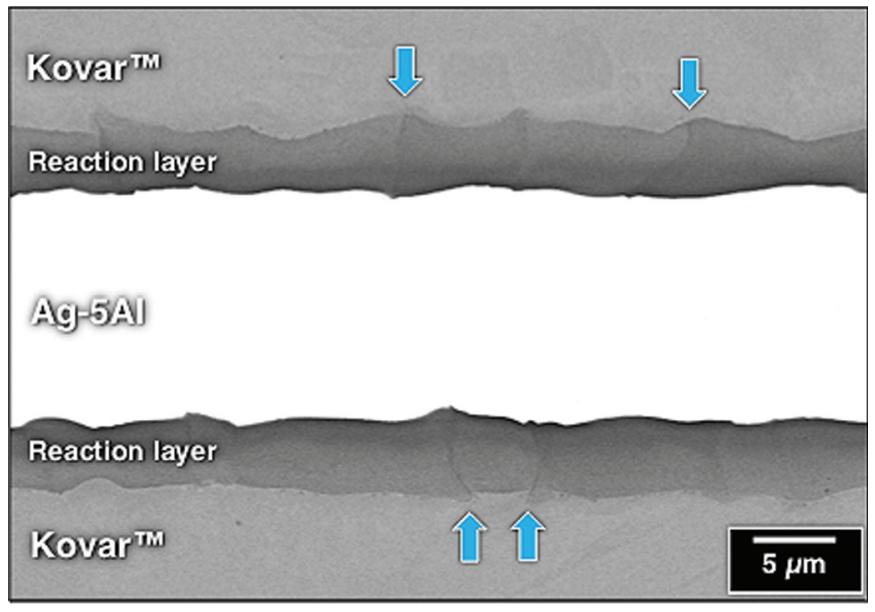

Fig. 10 - SEM photograph shows the braze joint made with the Ag-5Al filler metal. The brazing conditions were $965^{\circ} \mathrm{C}$ $\left(1769^{\circ} \mathrm{F}\right)$ and 5 -min time duration. The blue arrows denote vertical grain boundaries.

brazing conditions.

Two other features are shown in Fig. 9B. First, the dashed blue arrow indicates an $\mathrm{Al}$ gradient that signifies a roughly seven-micron-wide recrystallization zone in the Kovar ${ }^{\mathrm{TM}}$ base material. The $\mathrm{Al}$ concentration gradient is accompanied by a similar, but smaller, gradient of the Fe signal and opposite gradients for the $\mathrm{Ni}$ and $\mathrm{Co}$ concentrations. These behaviors suggest the exchange of $\mathrm{Al}$ for $\mathrm{Ni}$ and Co promotes recrystallization in Kovar $^{\mathrm{TM}}$. References could not be located that confirm or negate this hypothesis. The second feature is the $\mathrm{Fe}, \mathrm{Ni}$, and Co gradients that extended approximately two microns beyond the reaction layer/Ag-2Al interface into the filler metal. Second phase particles were not observed in the filler metal, which implies that $\mathrm{Fe}, \mathrm{Ni}$, and Co remained in solid solution.

The $\mathrm{Fe}, \mathrm{Ni}, \mathrm{Co}$, and $\mathrm{Al}$ contents were determined at the central region of the Ag-2Al filler metal field. Those concentrations (wt-\%) were $\mathrm{Fe}, 0.6 \pm 0.2 ; \mathrm{Ni}, 0.3 \pm 0.1$; and $\mathrm{Co}$, $0.3 \pm 0.1$. The mean $\mathrm{Al}$ concentration was $0.05 \mathrm{wt}-\%$, which is 
A

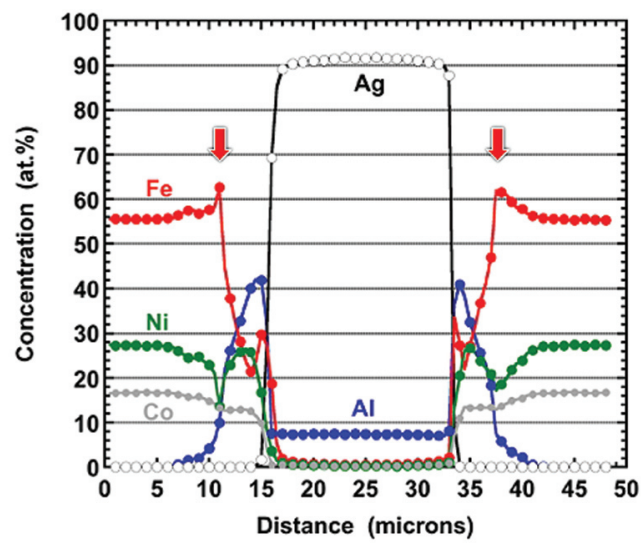

B

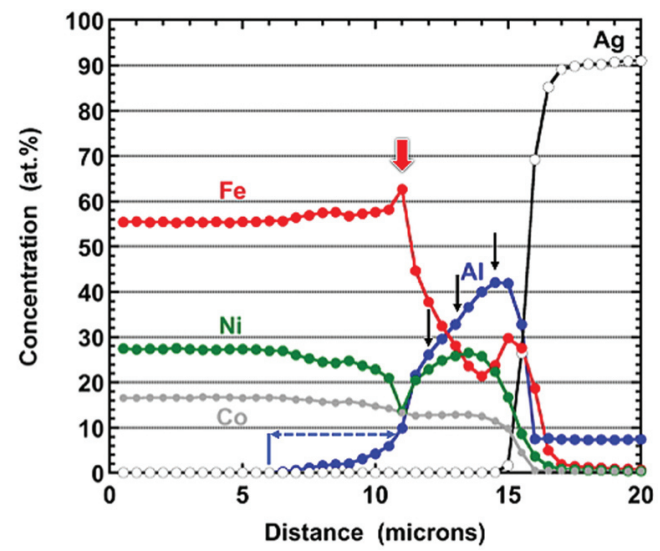

Fig. $11-A-E P M A$ data obtained from the braze joint fabricated with the Ag-5Al filler metal and brazing conditions of $965^{\circ} \mathrm{C}$ $\left(1769^{\circ} \mathrm{F}\right)$ and $5 \mathrm{~min}$. The red arrows indicate the Fe-rich reaction layer; B - enlarged EPMA trace targeted the left-hand side reaction layer. The three black arrows indicate the locations of the low-, medium-, and high-Al composition calculations. The dashed blue arrow identifies the recrystallization zone.

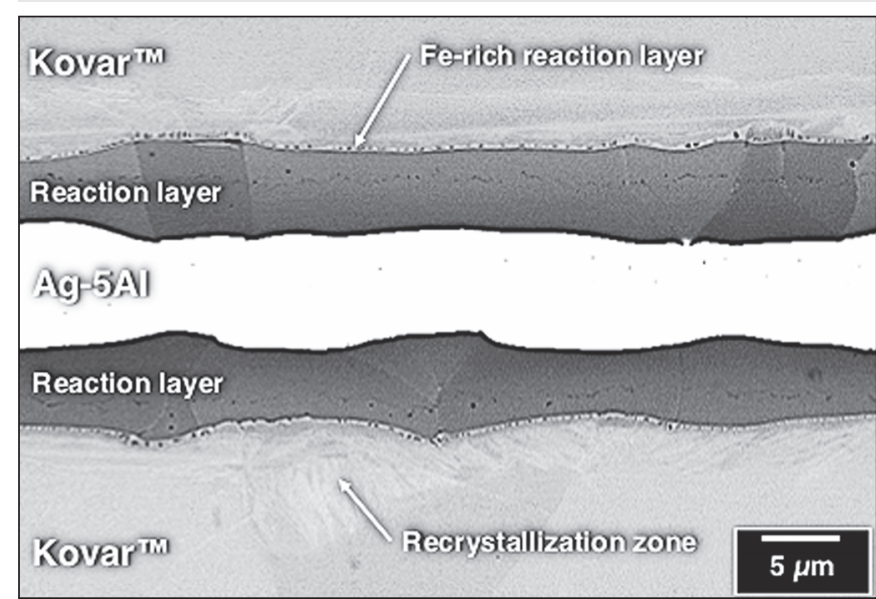

Fig. 12 - SEM photograph shows the braze joint fabricated from the Ag-5Al filler metal under the brazing conditions of

within the measurement error, thereby confirming its exhaustion in the reaction layers and recrystallization zones. The Fe, $\mathrm{Ni}$, and Co concentrations were more than twice those measured in the Ag-2Al filler metal when brazed at $965^{\circ} \mathrm{C}\left(1769^{\circ} \mathrm{F}\right)$ for $5 \mathrm{~min}$, indicating that the metastable, solid-solution condition for $\mathrm{Fe}, \mathrm{Ni}$, and $\mathrm{Co}$ in the filler metal had a wide composition range.

\section{Ag-5Al Filler Metal}

The reaction layers were examined that were formed by the Ag-5Al filler metal after brazing at $965^{\circ} \mathrm{C}\left(1769^{\circ} \mathrm{F}\right)$ and 5 min. Figure $2 \mathrm{C}$ shows that run-out was extensive on the Ko$\operatorname{var}^{\mathrm{TM}}$ flanges.

The joint microstructure is shown in Fig. 10. The reaction layer thickness was $4.9 \pm 0.6 \mu \mathrm{m}$ and independent of joint clearance. This thickness was significantly greater than that compiled for the Ag-2Al filler metal made with the same process conditions. Vertical grain boundaries (blue arrows) were observed in the reaction layers. Multiple phases were also discerned in the reaction layers by gray tone: darker gray was near the filler metal and lighter gray toward the Kovar ${ }^{\mathrm{TM}}$ base material. Cracks were not observed in either reaction layer. Lastly, second phases were absent from Ag-5Al filler metal.

The representative EPMA is shown in Fig. 11A. The red arrows identify the Fe-rich layer at the $\mathrm{Kovar}^{\mathrm{TM}} / \mathrm{reaction}$ layer interface. Significant reaction layers (Al peaks) formed at both interfaces. An enlarged view of the left-hand side interface is shown in Fig. 11B. The Fe peak, which is associated with the Fe-rich reaction layer (red arrow), was accompanied by a minimum in the Ni signal and small drop-off in the Co trace. Although these trends were also observed with the Ag-2Al alloy (Figs. 7 and 9), their magnitudes were greater in Fig. 11B.

The reaction layer in Fig. $11 \mathrm{~B}$ exhibited a broad $\mathrm{Al}$ peak and an Fe signal that fluctuated, having a minimum at approximately the layer midpoint and a small peak near the reaction layer/Ag-5Al filler metal interface. The Ni signal showed a single peak, the maximum of which coincided with the minimum in the Fe trace. The Co signal remained essentially constant across the reaction layer. Clearly, the EPMA profiles do not replicate the same relative proportions of these three elements as in the Kovar ${ }^{\mathrm{TM}}$ base material. The different $\mathrm{Fe}, \mathrm{Ni}$, and Co trends imply that each element is controlled by individual driving forces (chemical potentials) present during formation of the reaction layer.

The compositions were calculated for the low-, medium-, and high-Al regions of the reaction layer identified by the three black arrows in Fig. 11B:

- Low-Al composition: (Fe, Ni, Co) ${ }_{78 \pm 8} \mathrm{Al}_{22 \pm 3} \approx(\mathrm{Fe}, \mathrm{Ni}$, Co) ${ }_{7} \mathrm{Al}_{2}$

- Medium-Al composition: (Fe, Ni, Co) ${ }_{69 \pm 4} \mathrm{Al}_{31 \pm 2} \approx(\mathrm{Fe}, \mathrm{Ni}$, Co) ${ }_{7} \mathrm{Al}_{3}$

- High-Al composition: (Fe, Ni, Co $)_{59 \pm 2} \mathrm{Al}_{41.3 \pm 0.7} \approx(\mathrm{Fe}, \mathrm{Ni}$, Co) ${ }_{3} \mathrm{Al}_{2}$

The larger error terms reflected a greater variation of $\mathrm{Fe}$, $\mathrm{Ni}$, and $\mathrm{Al}$ concentrations across the reaction layer. The $\mathrm{Al}$ concentration range of $22 \pm 3-41.3 \pm 0.7$ at.- $\%$ was greater than that observed with the Ag-2Al filler metal (21 $\pm 3-27 \pm 2$ at.-\%) for the same brazing conditions.

The dashed blue arrow in Fig. 11B identified the Al diffusion gradient that extended nearly 5 microns into the Kovar ${ }^{\mathrm{TM}}$ 
A

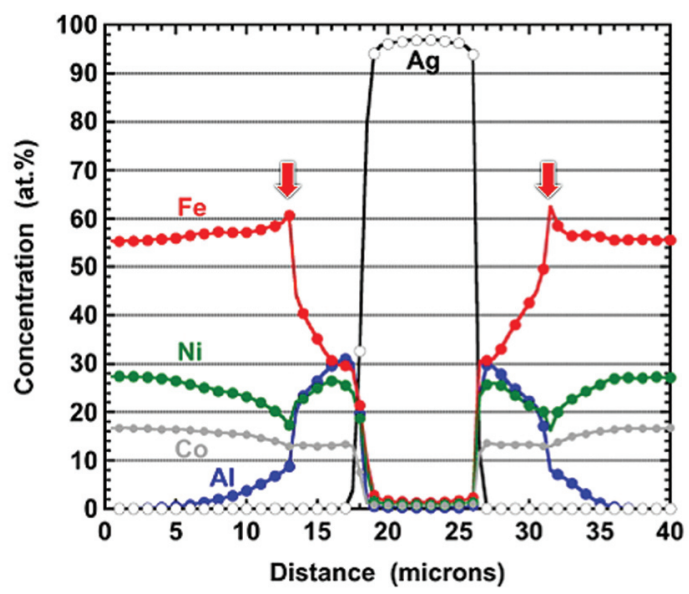

B

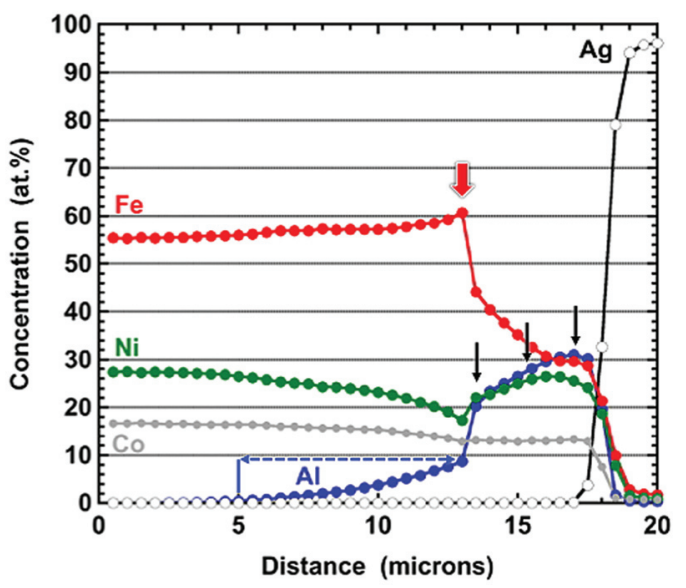

Fig. 13-A-Representative EPMA trace shows the braze joint fabricated with the Ag-5Al filler metal and brazing conditions of $995^{\circ} \mathrm{C}\left(1823^{\circ} \mathrm{F}\right)$ and $20 \mathrm{~min}$. The red arrows indicate the Fe-rich reaction layer; $\mathrm{B}$ - enlarged EPMA trace targets the left-hand side reaction. The three black arrows indicate the locations of the low-, medium-, and high-Al composition calculations. The blue arrow identifies a recrystallization zone.
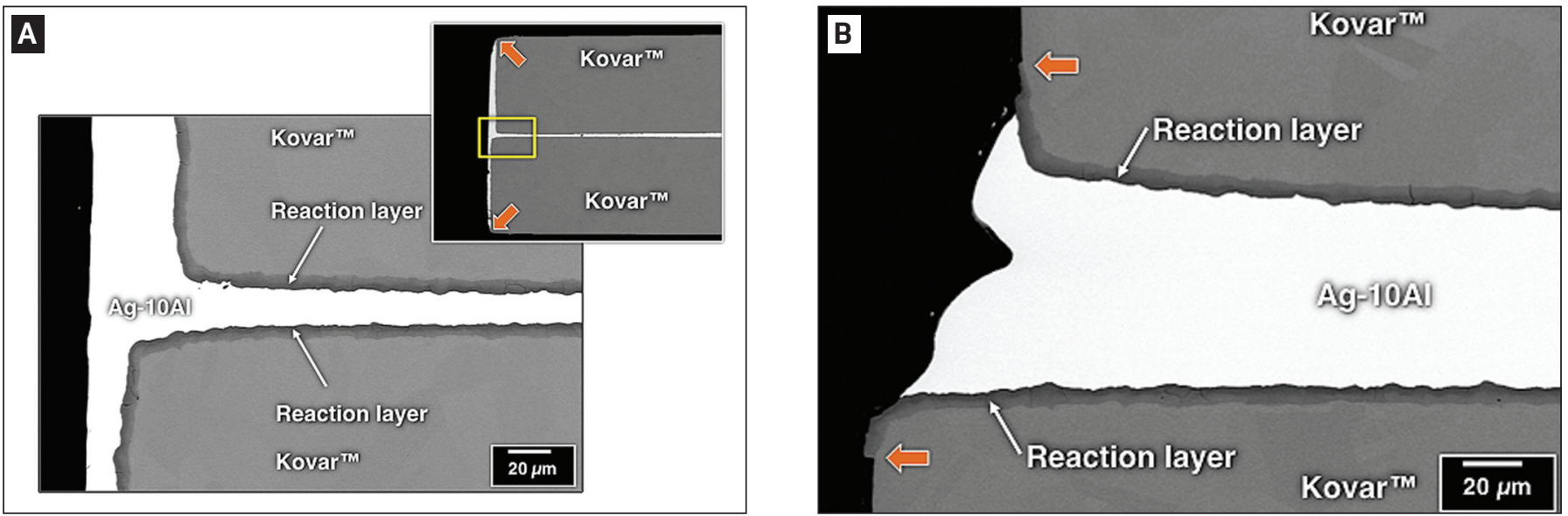

Fig. 14 - SEM images show the different extents of Ag-10Al wetting and spreading during brazing at $965^{\circ} \mathrm{C}\left(1769^{\circ} \mathrm{F}\right)$ for 5 min. $A-$ Inset SEM image shows run-out from the joint clearance, along Kovar ${ }^{\mathrm{TM}}$ edges, to the upper corners (orange arrows). The high magnification photograph shows formation of a thick reaction layer. B - SEM image taken of the same braze joint, but at a location where run-out was absent. The orange arrows denote the ends of the reaction layers.

base material and was indicative of the recrystallization zone.

Iron, $\mathrm{Ni}$, and Co exhibited gradients that extended approximately 2-3 $\mu \mathrm{m}$ into the filler metal from the latter's interface with the reaction layer - Fig. 11B. The SEM images did not resolve second phases in the Ag-5Al filler metal. The Al gradient was considerably steeper and approached the spatial resolution limit of the EPMA, which implies a relatively sharp termination of its concentration at the reaction layer.

The $\mathrm{Fe}, \mathrm{Ni}, \mathrm{Co}$, and $\mathrm{Al}$ concentrations were recorded in the center portion of Ag-5Al filler metal field (wt-\%): $\mathrm{Fe}$, $0.30 \pm 0.1 ; \mathrm{Ni}, 0.2 \pm 0.1 ; \mathrm{Co}, 0.2 \pm 0.1 ;$ and $\mathrm{Al}, 1.8 \pm 0.1$. The Fe, $\mathrm{Ni}$, and Co levels were statistically similar to those measured with the Ag-2Al filler metal after brazing at $965^{\circ} \mathrm{C}\left(1769^{\circ} \mathrm{F}\right)$ for $5 \mathrm{~min}$. However, the $\mathrm{Al}$ concentration was significantly higher at $1.8 \pm 0.1 \mathrm{wt}-\%$. Clearly, the $\mathrm{Al}$ was not fully consumed by the reaction layer formation. The Ag-Al binary alloy phase diagram indicated this quantity of Al should re- main in complete solid solution within the Ag matrix down to $25^{\circ} \mathrm{C}\left(77^{\circ} \mathrm{F}\right)$ (Ref. 5). In fact, second-phase particles were not detected in the filler metal.

Scanning electron microscope photographs were taken of Ag-5Al braze joints fabricated at $965^{\circ} \mathrm{C}\left(1769^{\circ} \mathrm{F}\right)$ and $20 \mathrm{~min}$ as well as $995^{\circ} \mathrm{C}\left(1823^{\circ} \mathrm{F}\right)$ and $5 \mathrm{~min}$. Figure $2 \mathrm{C}$ shows both cases to have experienced extensive run-out. However, the longer brazing time and/or higher brazing temperature did not generate observable changes to the reaction layer, the filler metal, or the Kovar $^{\mathrm{TM}}$ base material microstructures. A few scattered pores were observed in the reaction layers. The reaction layer thicknesses were $4.7 \pm 0.8 \mu \mathrm{m}\left[965^{\circ} \mathrm{C}\right.$ $\left(1769^{\circ} \mathrm{F}\right)$ and $\left.20 \mathrm{~min}\right]$ and $4.8 \pm 0.4 \mu \mathrm{m}\left[995^{\circ} \mathrm{C}\left(1769^{\circ} \mathrm{F}\right)\right.$ and $5 \mathrm{~min}]$. These thickness values were insensitive to joint clearance and were statistically the same as the $4.9 \pm 0.6 \mu \mathrm{m}$ value that was measured after brazing at $965^{\circ} \mathrm{C}\left(1769^{\circ} \mathrm{F}\right)$ and 5 min. Cracks were absent from the layers.

The SEM micrograph in Fig. 12 shows the braze joint 


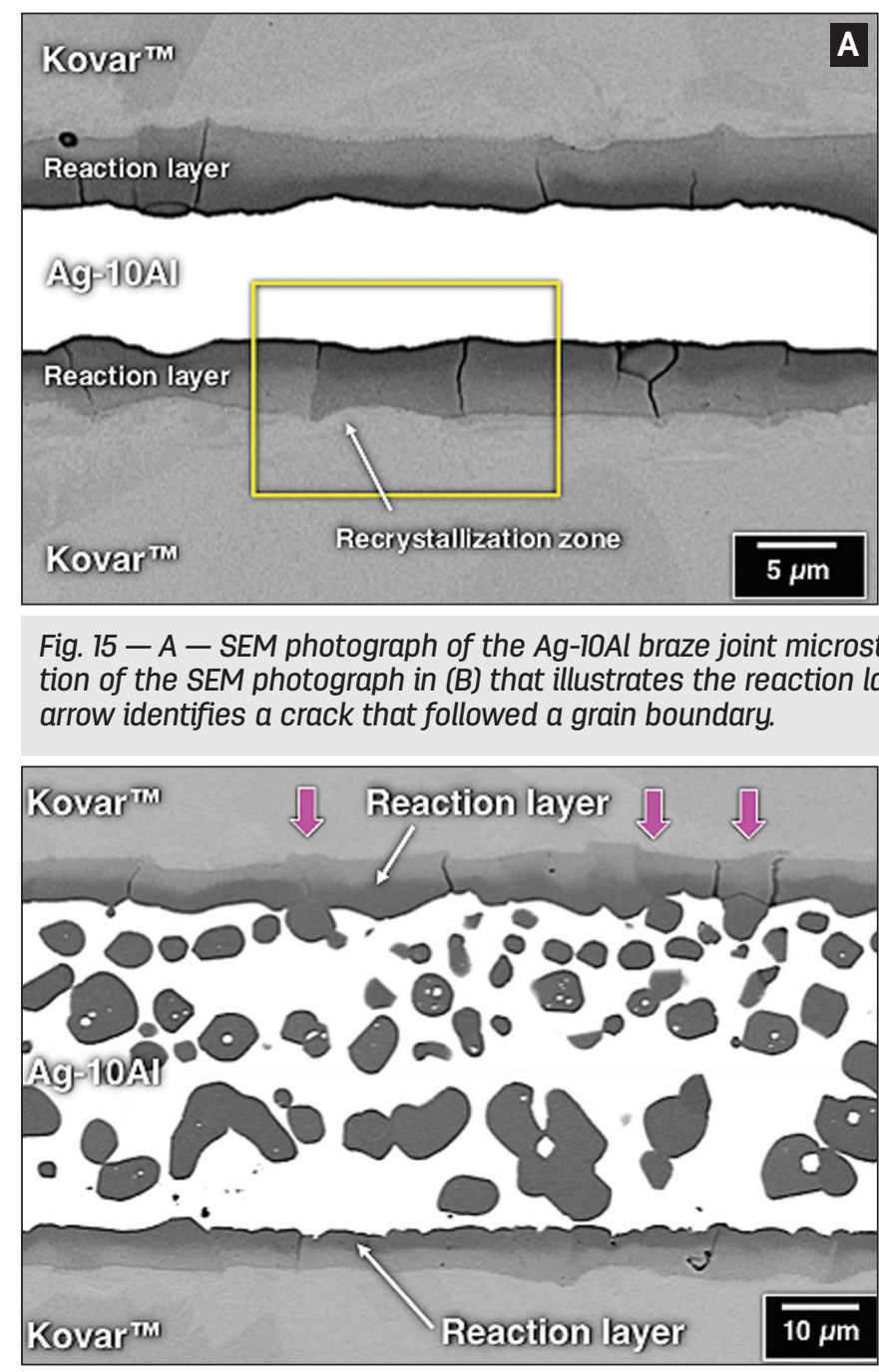

Fig. 16 - SEM photograph shows a location having the particle phase in the $\mathrm{Ag}-10 \mathrm{Al}$ braze joint formed at $965^{\circ} \mathrm{C}\left(1769^{\circ} \mathrm{F}\right)$

formed by the Ag-5Al filler metal when the brazing conditions were $995^{\circ} \mathrm{C}\left(1769^{\circ} \mathrm{F}\right)$ and $20 \mathrm{~min}$. Run-out was very extensive as shown in Fig. 2C. Although the joint clearance varied from 6.4 to $28.2 \mu \mathrm{m}$, the reaction layer thickness was relatively constant with a value of $5.5 \pm 0.6 \mu \mathrm{m}$. Vertical grain boundaries were observed in the layers. Cracks were absent. The Fe-rich reaction layer was prominent at the reaction layer/Kovar ${ }^{\mathrm{TM}}$ base material interface as was recrystallization in the Kovar ${ }^{\mathrm{TM}}$ base material.

The representative EPMA plot is shown in Fig. 13A. The interface reaction layers are identified by the $\mathrm{Al}$ peak. The red arrows locate the Fe-rich layer between the reaction layer and Kovar $^{\mathrm{TM}}$ base material. The details of the interface microstructure are shown by the expanded view of the lefthand reaction layer in Fig. 13B. The Fe-rich phase (red arrow) was accompanied by a minimum in the Ni concentration and drop off of the Co signal. The dashed blue arrow shows the extensive diffusion of $\mathrm{Al}$ into the $\mathrm{Kovar}^{\mathrm{TM}}$ base material that was concurrent with the recrystallization zone. That Al gradient was accompanied by a similar gradient in the Fe concentration and opposite gradients of both $\mathrm{Ni}$ and, to a lesser degree, $\mathrm{Co}$.

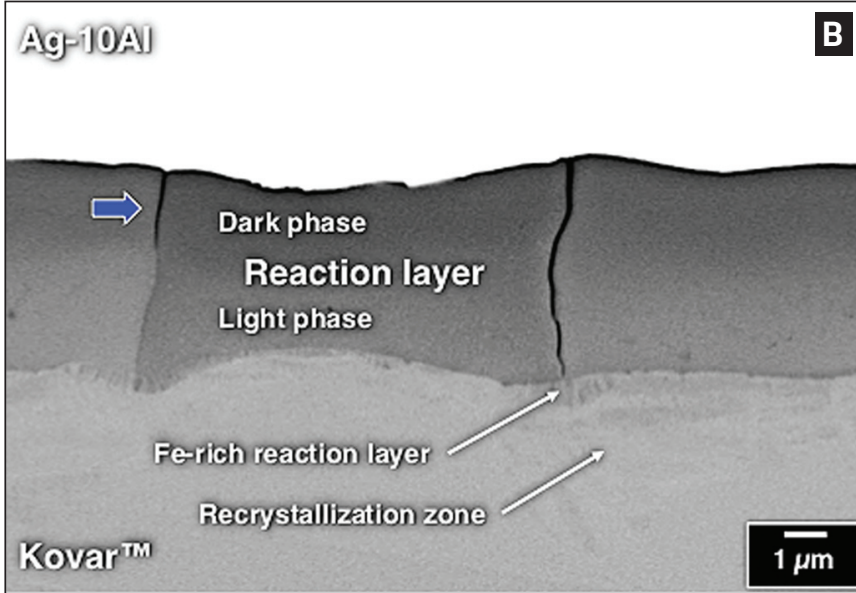

The $\mathrm{Al}$ and $\mathrm{Ni}$ signals showed maxima in the reaction layer - Fig. 13B. The Fe concentration gradually decreased to a minimum just before the reaction layer/filler metal interface. An additional Fe peak was not present at that interface as was observed when the brazing conditions were $965^{\circ} \mathrm{C}\left(1769^{\circ} \mathrm{F}\right)$ and $5 \mathrm{~min}$ (Fig. 11B). The Co signal remained largely constant in the reaction layer. Lastly, $\mathrm{Fe}, \mathrm{Ni}$, and $\mathrm{Co}$ exhibited decreasing concentrations that extended approximately $2-3 \mu \mathrm{m}$ into the $\mathrm{Ag}-5 \mathrm{Al}$ filler metal beyond the reaction layer.

The EPMA graph (Fig. 13B) shows the three black arrows that identify the locations where the determination was made of the low-, medium-, and high-Al phase compositions listed below:

- Low-Al composition: $(\mathrm{Fe}, \mathrm{Ni}, \mathrm{Co})_{80 \pm 2} \mathrm{Al}_{20.3 \pm 0.7} \approx(\mathrm{Fe}, \mathrm{Ni}$, $\mathrm{Co})_{4} \mathrm{Al}$

- Medium-Al composition: $(\mathrm{Fe}, \mathrm{Ni}, \mathrm{Co})_{74 \pm 2} \mathrm{Al}_{26 \pm 1} \approx(\mathrm{Fe}, \mathrm{Ni}$, Co) ${ }_{3} \mathrm{Al}$

- High-Al composition: $(\mathrm{Fe}, \mathrm{Ni}, \mathrm{Co})_{70 \pm 2} \mathrm{Al}_{30 \pm 1} \approx(\mathrm{Fe}, \mathrm{Ni}$, Co) ${ }_{7} \mathrm{Al}_{3}$

These compositions were compared to those measured in reaction layers created under the brazing conditions of $965^{\circ} \mathrm{C}\left(1769^{\circ} \mathrm{F}\right)$ and $5 \mathrm{~min}$. The low-Al composition, which developed closest to the Kovar $^{\mathrm{TM}}$ base material, was nearly the same. On the other hand, the medium- and high-Al compositions had significantly lower $\mathrm{Al}$ concentrations after brazing at $995^{\circ} \mathrm{C}\left(1823^{\circ} \mathrm{F}\right)$ for $20 \mathrm{~min}$ vs. the $965^{\circ} \mathrm{C}$ $\left(1769^{\circ} \mathrm{F}\right), 5$ min brazing conditions.

The $\mathrm{Fe}, \mathrm{Ni}, \mathrm{Co}$, and $\mathrm{Al}$ concentrations were measured in the Ag-5Al filler metal. Those values were (wt-\%): Fe, $0.8 \pm 0.1 ; \mathrm{Ni}, 0.5 \pm 0.1$; and $\mathrm{Co}, 0.4 \pm 0.1$. The more severe brazing conditions caused the concentrations of $\mathrm{Fe}, \mathrm{Ni}$, and $\mathrm{Co}$ to more than double those measured after brazing at $965^{\circ} \mathrm{C}$ $\left(1769^{\circ} \mathrm{F}\right)$ for $5 \mathrm{~min}$. Nevertheless, these concentrations remained below the solubility limit upon solidification. The SEM images confirmed an absence of precipitate phases in the filler metal.

The mean $\mathrm{Al}$ concentration was $0.07 \mathrm{wt}-\%$, which is within the measurement error. This result implies that the $\mathrm{Al}$ content was fully consumed from the Ag-5Al filler metal. Figure $11 \mathrm{~A}$ and $\mathrm{B}$ indicates that $1.8 \pm 0.1 \mathrm{wt}-\%$ of $\mathrm{Al}$ re- 

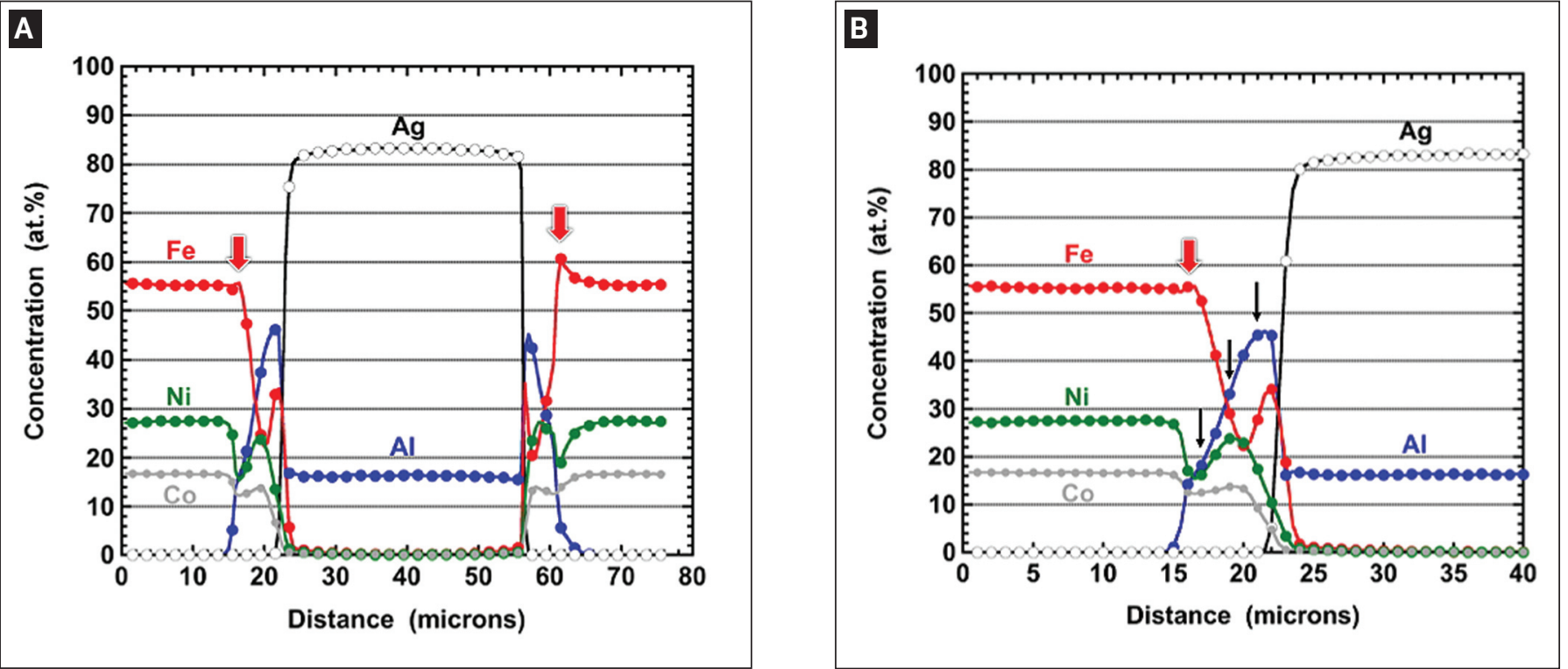

Fig. $17-A-E P M A$ data obtained from the braze joint fabricated with the Ag-10Al filler metal and brazing conditions of $965^{\circ} \mathrm{C}$ $\left(1769^{\circ} \mathrm{F}\right)$ and $5 \mathrm{~min}$. The red arrows indicated the Fe-rich reaction layers. B - Enlarged EPMA trace shows the left-hand side reaction layer. The black arrows identify the locations where compositions were measured representing low-, medium-, and high-Al contents (left to right).
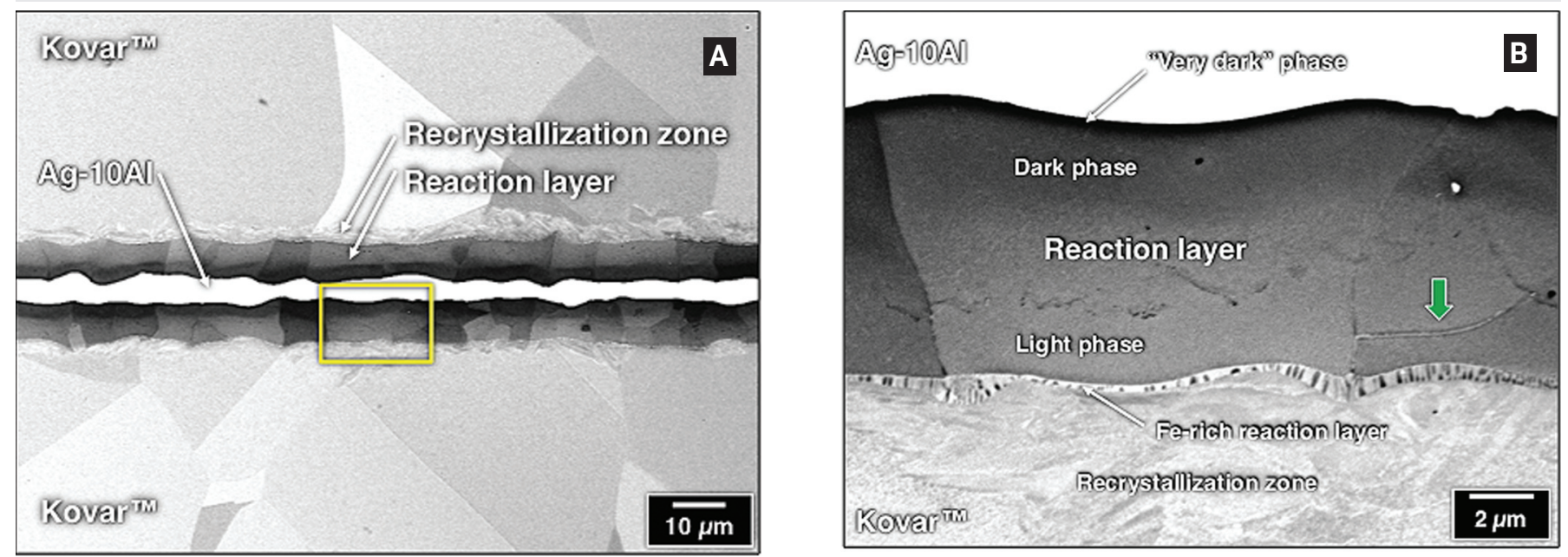

Fig. $18-A-S E M$ photograph shows the braze joint formed by the Ag-10Al filler metal under the process conditions of $995^{\circ} \mathrm{C}$ $\left(1823^{\circ} \mathrm{F}\right)$ and $20 \mathrm{~min}$. The yellow box indicates the location of the high magnification photograph in B. B - SEM image illustrates the reaction layer microstructure, including three phases identified by gray tone: light, dark, and "very dark." The green arrow indicates a horizontal grain boundary.

mained in the same filler metal under the less severe brazing parameters of $965^{\circ} \mathrm{C}\left(1769^{\circ} \mathrm{F}\right)$ and $5 \mathrm{~min}$.

Together, the Al concentrations in the reaction layers as well as Al remaining filler metal appear to be counterintuitive. That is, the more severe brazing conditions caused less $\mathrm{Al}$ in the reaction layers and less $\mathrm{Al}$ remaining in the same Ag-5Al filler metal than did the less severe brazing conditions. This apparent discrepancy can be explained by the fact the $995^{\circ} \mathrm{C}\left(1769^{\circ} \mathrm{F}\right), 20 \mathrm{~min}$ brazing conditions caused thicker reaction layers $(5.5 \pm 0.6 \mu \mathrm{m})$, a greater degree of recrystallization in the Kovar ${ }^{\mathrm{TM}}$ base material, and more extensive run-out. However, given how quickly the $\mathrm{Al} / \mathrm{Kovar}^{\mathrm{TM}}$ base material reaction occurs, it is unlikely the reduced $\mathrm{Al}$ concentration in the reaction layer was caused by these ex- trinsic factors. Rather, the reaction layer compositions were established by the chemical potential that was controlled by the filler metal composition as well as brazing temperature and, to a lesser degree, brazing time.

\section{Ag-10Al Filler Metal}

The optical images in Fig. 2D showed extensive run-out by the Ag-10Al filler metal under all brazing conditions. This sample allowed for a qualitative assessment to be made of the roles of capillary flow and reaction layer composition on runout. Recall that capillary action allowed the Ag-0Al filler metal to flow through the joint clearance. However, a reaction layer was absent and concurrently, the Ag-0Al filler metal did not 


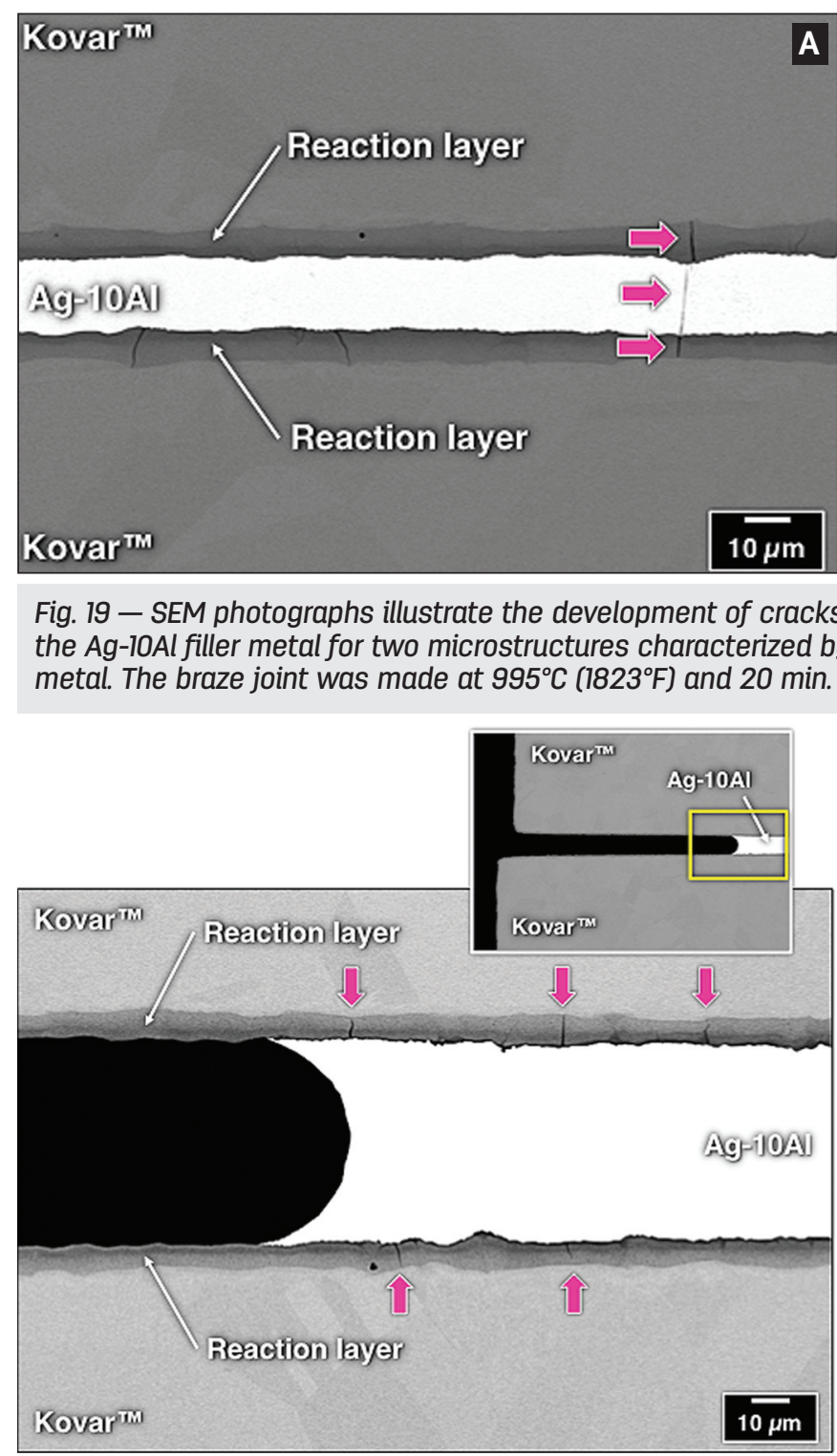

Fig. 20 - SEM images illustrate the microstructure at the edge of capillary flow by the Ag-10Al filler metal. The inset picture shows the overall joint configuration and identifies the location (yellow box) of the high-magnification photograph. The magenta arrows in the latter point to examples of cracks in the reaction layers. The braze joint was made at $995^{\circ} \mathrm{C}\left(1823^{\circ} \mathrm{F}\right)$ and $20 \mathrm{~min}$.

demonstrate run-out. On the other hand, the $\mathrm{Ag}-10 \mathrm{Al}$ alloy shows extensive run-out as shown in Fig. $14 \mathrm{~A}\left[965^{\circ} \mathrm{C}\right.$ $\left.\left(1769^{\circ} \mathrm{F}\right), 5 \mathrm{~min}\right]$. The filler metal flowed to the end of the joint clearance, up along the flange edges, and stopped at the top corners (orange arrows). Capillary action is not present beyond the joint clearance; therefore, the reaction layers (high magnification image) supported the run-out. A second location is shown in Fig. 14B. The Ag-10 filler metal wet and spread only to the edge of the joint clearance. However, the reaction layer continued a short distance further up each

2 . The same argument pertains to the absence of traditional runout lobes in the sessile drop experiments of Part 1 - capillary action was not active in that configuration.

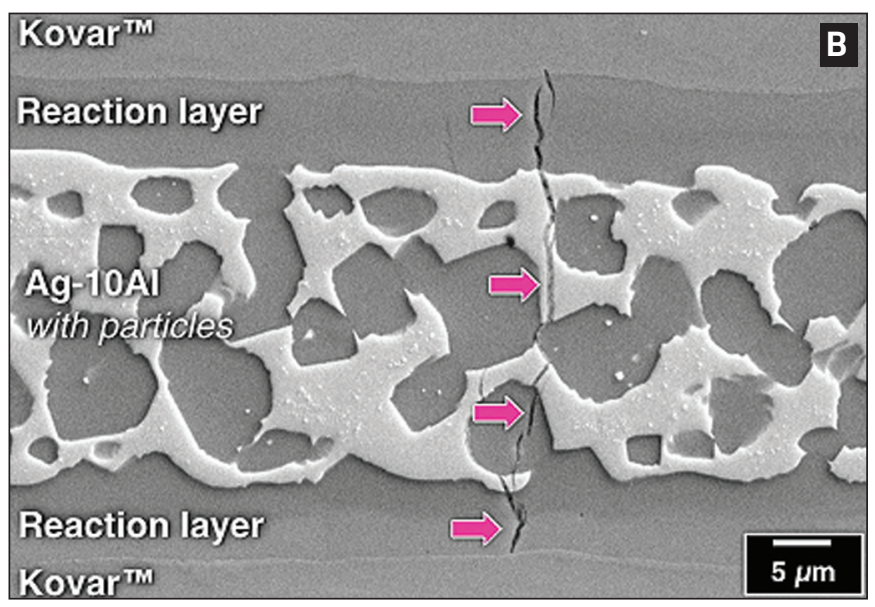

Kovar $^{\text {Th }}$ 
A

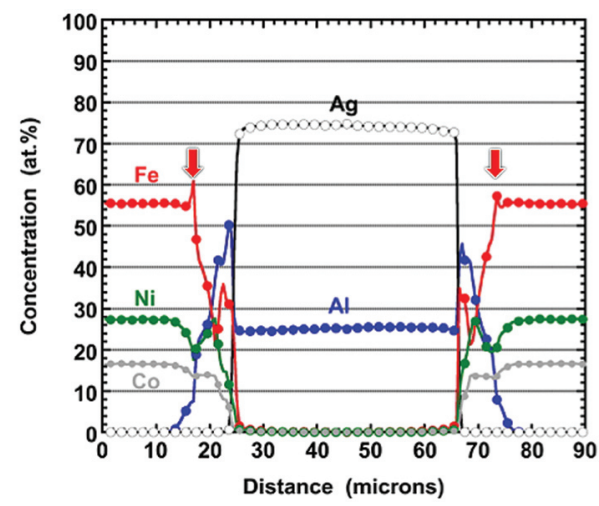

B

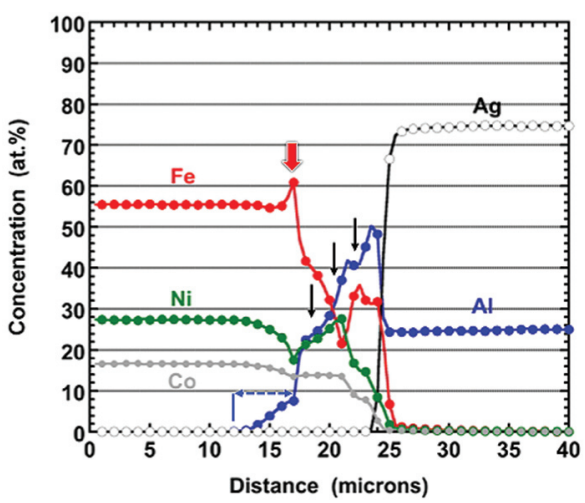

Fig. $21-A-E P M A$ graph compiled from the Ag-10Al braze joint formed at $995^{\circ} \mathrm{C}\left(1823^{\circ} \mathrm{F}\right)$ and 20 min. The red arrows indicate the Fe-rich layer at the Kovar ${ }^{T M}$ base material/reaction layer interface. B - Enlarged version of the left-hand side reaction layer in A. The black arrows indicate the locations at which were established the low-, medium-, and high-Al phase compositions. The blue arrow shows the extent of the recrystallization zone.

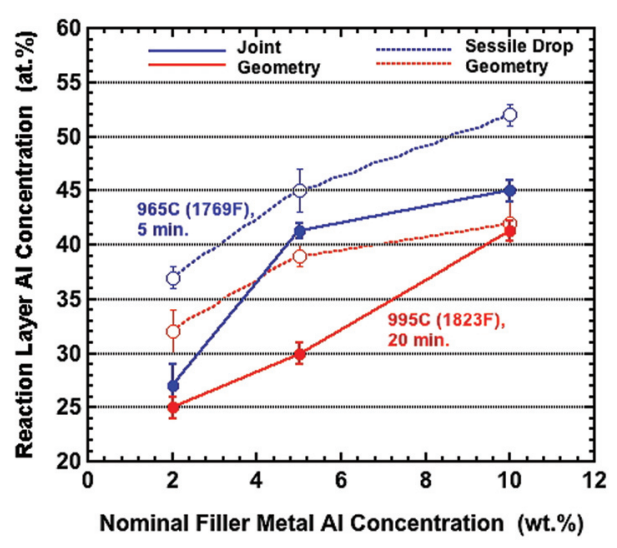

Fig. 22 - Aluminum concentration (at.-\%) in the reaction layer contacting the filler metal is plotted as a function of the nominal Al concentration (wt-\%) of the filler metal. The blue and red plots show data for the brazing processes of $965^{\circ} \mathrm{C}\left(1769^{\circ} \mathrm{F}\right), 5 \mathrm{~min}$, and $995^{\circ} \mathrm{C}\left(1823^{\circ} \mathrm{F}\right), 20 \mathrm{~min}$, respectively. The closed symbols and solid lines represent the joint configuration; the open symbols and dashed lines represent the sessile drop data from Part 1.

the following concentrations: Fe, $0.2 \pm 0.1 ; \mathrm{Ni}, 0.1 \pm 0.1$, and Co, $0.1 \pm 0.1 \mathrm{wt}-\%$, respectively. These values, individually and summed together $(0.4 \pm 0.2 \mathrm{wt}-\%)$, were less than similar metrics for the previous Ag-xAl filler cases. This observation would be unexpected if the $\mathrm{Al}$ content of the filler metal was the driving force for $\mathrm{Fe}, \mathrm{Ni}$, and Co dissolution. Apparently, such is not the case.

Figure 17B provides an enlarged EPMA plot of the lefthand interface. This location did not exhibit significant recrystallization in the $\mathrm{Kovar}^{\mathrm{TM}}$ base material. The Ni and Co signals exhibited large and small minima, respectively, that coincided with the Fe-rich reaction layer (red arrow). The Fe and Ni concentrations exhibited large fluctuations within the reaction layer that were out of step with each other. The Co signal exhibited a concentration profile similar to the $\mathrm{Ni}$ signal, but having a lesser amplitude.

Referring to the immediate interface between the reac-

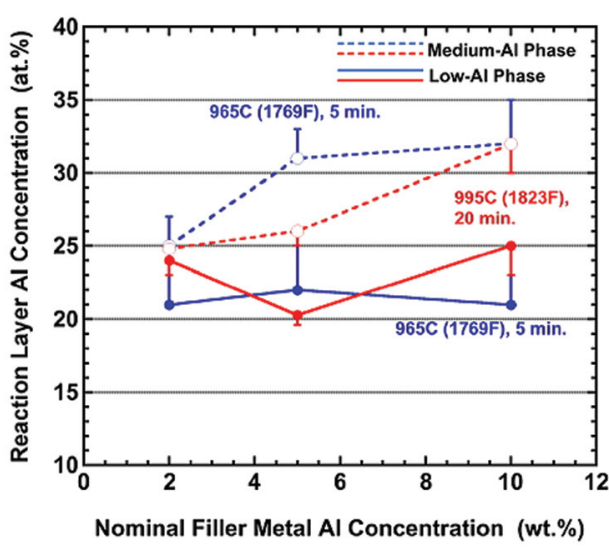

Fig. 23 - Aluminum concentration (at.-\%) in the medium-Al (dashed lines) and low-Al (solid lines) reaction layers is plotted as a function of the nominal Al concentration (wt-\%) of the filler metal. The blue and red plots represent the brazing processes of $965^{\circ} \mathrm{C}\left(1769^{\circ} \mathrm{F}\right), 5 \mathrm{~min}$, and $995^{\circ} \mathrm{C}\left(1823^{\circ} \mathrm{F}\right), 20 \mathrm{~min}$.

tion layer and filler metal field, the $\mathrm{Fe}, \mathrm{Ni}$, and Co signals exhibited a small gradient extending approximately 1-2 $\mu \mathrm{m}$ into the filler metal, which is at the resolution limit of the EPMA technique.

The three black arrows identify the locations at which were calculated the following low-, medium-, and high-Al phases (left to right):

- Low-Al composition: (Fe, Ni, Co $)_{79 \pm 8} \mathrm{Al}_{21 \pm 2} \approx(\mathrm{Fe}, \mathrm{Ni}$, Co) ${ }_{4} \mathrm{Al}$

- Medium-Al composition: (Fe, Ni, Co $)_{68 \pm 6} \mathrm{Al}_{32 \pm 3} \approx(\mathrm{Fe}, \mathrm{Ni}$, Co) ${ }_{2} \mathrm{Al}$

- High-Al composition: (Fe, Ni, Co $)_{55 \pm 6} \mathrm{Al}_{45 \pm 1} \approx(\mathrm{Fe}, \mathrm{Ni}$, Co) ${ }_{6} \mathrm{Al}_{5}$

The above compositions were compared to those observed with the Ag-5Al filler metal when it was brazed with the same parameters of $965^{\circ} \mathrm{C}\left(1769^{\circ} \mathrm{F}\right)$ and $5 \mathrm{~min}$. The lowand medium-Al phases had similar compositions to within experimental error. The high-Al phases differed slightly in Al concentrations: $45 \pm 1$ at.- $\%$ for the current $\mathrm{Ag}-10 \mathrm{Al}$ alloy versus $41 \pm 2$ at.- $\%$ for the previous $\mathrm{Ag}-5 \mathrm{Al}$ alloy. 


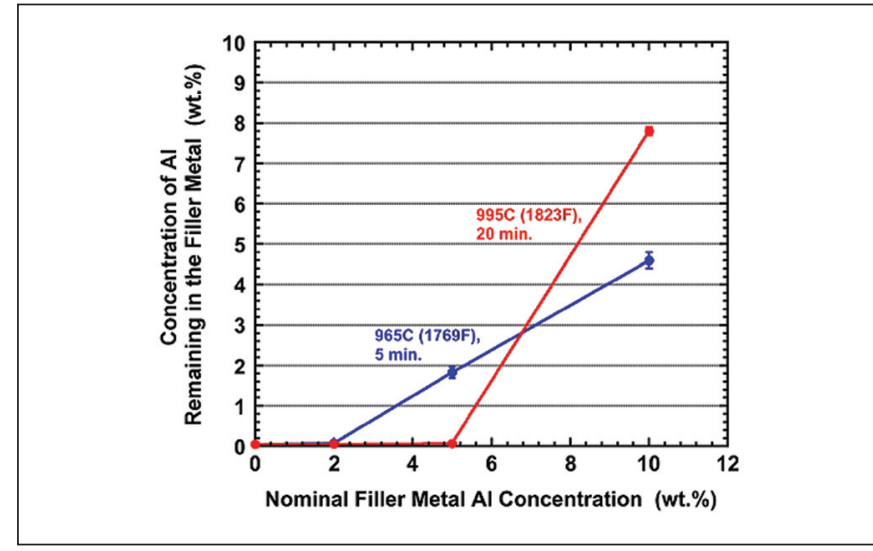

Fig. 24 - Graph shows the amount of Al remaining in the filler metal as a function of the latter's nominal (or starting) Al content for the brazing process parameters of $965^{\circ} \mathrm{C}\left(1769^{\circ} \mathrm{F}\right)$, $5 \mathrm{~min}$ (blue plot), and $995^{\circ} \mathrm{C}\left(1823^{\circ} \mathrm{F}\right), 20 \mathrm{~min}$ (red plot).

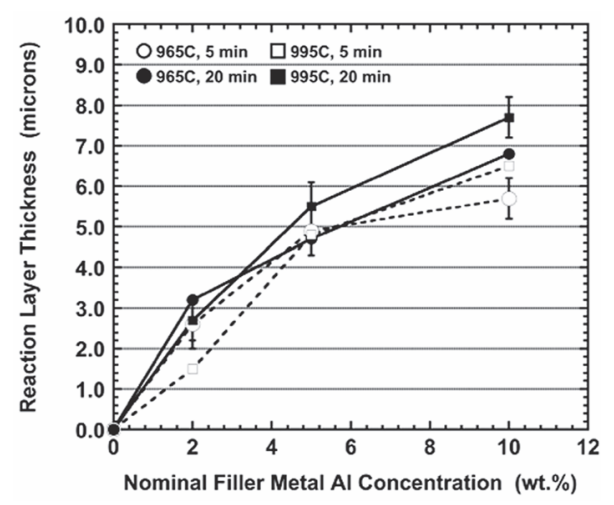

Fig. 26 - Graph shows the reaction layer thickness as a function of the nominal Al content of the filler metal for all four brazing process conditions.

Despite the small differences in composition, the reaction layer was susceptible to cracking in the Ag-10Al filler metal but not so in the Ag-5Al filler metal. There are two scenarios, acting either separately or in combination, that explain the cracking propensities: $\mathrm{A}$ ) the slightly higher $\mathrm{Al}$ concentration in the high-Al phase formed by the $\mathrm{Ag}-10 \mathrm{Al}$ alloy or $\mathrm{B}$ ) the higher $\mathrm{Al}$ concentration remaining in the Ag-10Al filler metal increased the residual stresses in the reaction layer. The latter scenario assumes the higher $\mathrm{Al}$ content in the filler metal reduced its ductility, causing it to be less compliant toward relieving coefficient of thermal expansion (CTE) mismatch residual stresses. These scenarios are discussed further in the following section.

The braze joints were examined that were brazed at $965^{\circ} \mathrm{C}$ $\left(1769^{\circ} \mathrm{F}\right)$ for $20 \mathrm{~min}$. Figure 2D shows extensive run-out of the filler metal. The braze joint microstructures were very similar to those observed after 5 min - Figs. 14-16. Cracks initiated in the high-Al phase next to the filler metal and stopped in the low-Al phase prior to reaching the Kovar ${ }^{\mathrm{TM}}$ base material. The reaction layer thickness was $6.8 \pm 0.7 \mu \mathrm{m}$ and did not show a significant dependence on joint clearance. This value was higher than that measured after $5 \min (5.7 \pm 0.5 \mu \mathrm{m})$ and exceeded the thicknesses of $3.2 \pm 0.8$ and $4.7 \pm 0.8 \mu \mathrm{m}$ that formed with the $\mathrm{Ag}-2 \mathrm{Al}$ and $\mathrm{Ag}-5 \mathrm{Al}$ filler metals, respectively, under

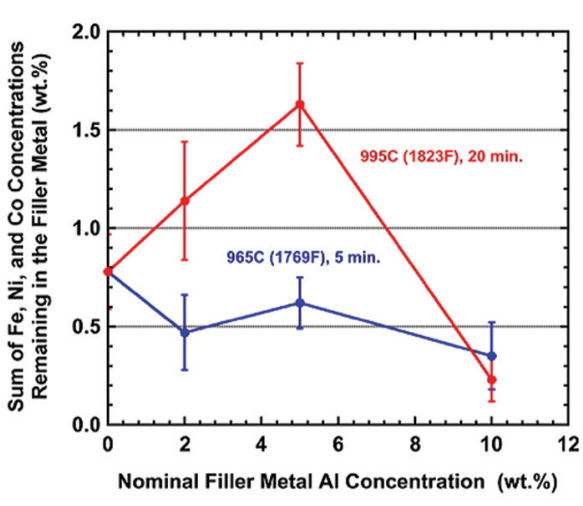

Fig. 25 - Sum of $\mathrm{Fe}, \mathrm{Ni}$, and $\mathrm{Co}$ in the filler metal is plotted as a function of the nominal Al content of the filler metal for the brazing process parameters of $965^{\circ} \mathrm{C}\left(1769^{\circ} \mathrm{F}\right), 5 \mathrm{~min}$ (blue plot), and $995^{\circ} \mathrm{C}\left(1823^{\circ} \mathrm{F}\right), 20 \mathrm{~min}$ (red plot).

the same brazing conditions. A few clearance locations had particles present in the filler metal.

The Ag-10Al braze joints, which were fabricated at $995^{\circ} \mathrm{C}$ $\left(1823^{\circ} \mathrm{F}\right)$ and $5 \mathrm{~min}$, showed extensive run-out per Fig. 2D. The same crack morphology was observed in the reaction layers as described above. The reaction layer thickness was $6.5 \pm 0.5 \mu \mathrm{m}$.

The Ag-10Al braze joints were examined that were made at $995^{\circ} \mathrm{C}\left(1823^{\circ} \mathrm{F}\right)$ and $20 \mathrm{~min}$. The backscattered electron (BSE) channeling image mode was used in Fig. 18A to accentuate the grain structure in the reaction layers as well as extensive recrystallization zones in the Kovar ${ }^{\mathrm{TM}}$ base material. This joint clearance was very small, averaging a little over $5 \mu \mathrm{m}$. Some locations exhibited joint clearances as large as $53 \mu \mathrm{m}$, yet the reaction layers had a consistent thickness of $7.7 \pm 0.5 \mu \mathrm{m}$.

Figure 18A shows the grain boundaries to have generally a vertical or columnar orientation. However, horizontal grain boundaries were also observed in the layers. Figure $18 \mathrm{~B}$ is a high-magnification image of the reaction layer location identified by the yellow box in Fig. 18A. The green arrow points to one such horizontal boundary. The presence of horizontal boundaries implies that further grain development occurred after initial formation of the reaction layer.

The SEM image in Fig. 18B shows the Fe-rich phase along the reaction layer/Kovar ${ }^{\mathrm{TM}}$ base material interface and extensive recrystallization. Three gray tones - light, dark, and "very dark" - suggested that three-phase composition comprised the reaction layer composition.

The SEM images in Fig. 19 show the crack morphologies of the Ag-10Al braze joint. Figure 19A shows a crack that crossed the Ag-10Al filler and Fig. 19B identifies a crack in the filler metal and particles. The presence of cracks in the filler metal implies that it has a lower ductility. The crack behaviors lend further evidence of the root-cause scenario (B), that is, a reduced ability of the filler metal to relieve CTE mismatch residual stresses in the braze joint. The particles showed a singular composition that was equivalent to that of the high-Al, reaction layer phase listed, below, for this brazing condition.

The Ag-10Al braze joint $\left[995^{\circ} \mathrm{C}\left(1823^{\circ} \mathrm{F}\right), 20 \mathrm{~min}\right.$ ] was examined at a terminus of its capillary flow - Fig. 20. The in- 
set image shows filler metal flow through the joint clearance. The high-magnification photograph (yellow box in the inset photograph) shows that reaction layers had formed beyond the filler metal on both sides of the empty clearance. Cracks were absent from the reaction layer on both sides of the unfilled clearance, but present in the reaction layers adjacent to the filler metal. This observation implies that the cracks are not an intrinsic property of the reaction layer. Rather, the presence of Ag-10Al filler metal is necessary for their formation.

The EPMA data are shown in Fig. 21A for the entire braze joint. The reaction layers are indicated by the $\mathrm{Al}$ peaks at both interfaces. Of particular note was the elevated $\mathrm{Al}$ concentration remaining in the filler metal, $7.8 \pm 0.1 \mathrm{wt}-\%$. This value represented a significant proportion of the $10-\mathrm{wt}-\% \mathrm{Al}$ originally present in the filler metal and is well in excess of the $4.6 \pm 0.2$-wt- $\%$ present after brazing at $965^{\circ} \mathrm{C}\left(1769^{\circ} \mathrm{F}\right)$ for $5 \mathrm{~min}$. The expectation was that the higher brazing temperature and longer time would promote a greater extent of reaction between $\mathrm{Al}$ and the $\mathrm{Kovar}^{\mathrm{TM}}$ base material, thus leaving the filler metal with lower $\mathrm{Al}$ concentration. This behavior reaffirms the earlier stipulation that brazing temperature and time determine the driving force (chemical potential) of the reaction as opposed to simply accelerating the latter's thermally activated, rate kinetics.

The concentrations were compiled of $\mathrm{Fe}, \mathrm{Ni}$, and $\mathrm{Co}$ in the filler metal. Those values were $\mathrm{Fe}, 0.10 \pm 0.1 ; \mathrm{Ni}, 0.1 \pm 0.1$; Co, $0.1 \pm 0.1 \mathrm{wt}-\%$, which were below their respective solubility limits in Ag. As such, second phases were not observed in the filler metal. Also, these concentrations were similar to those measured in the filler metal after brazing at $965^{\circ} \mathrm{C}$ $\left(1769^{\circ} \mathrm{F}\right)$ and $5 \mathrm{~min}$. This observation implies that the dependency of base material dissolution on the brazing process parameters, like the reaction layer formation, was not based simply on thermal activation (kinetics) effects.

The details of the interface microstructure are demonstrated in Fig. 21B, which is the EMPA trace of the left-hand side of the joint. The red arrow indicates the Fe-rich phase adjacent to the Kovar ${ }^{\mathrm{TM}}$ base material. Recrystallization (dashed blue arrow) was extensive in the latter; albeit, it was more limited at this particular location. As observed in previous analyses, the Fe peak (red arrow) is accompanied by a minimum in the Ni concentration and a drop off by the Co signal. The $\mathrm{Al}$ concentration increased by and large monotonically toward the filler metal interface. The Fe and Ni concentrations fluctuated in a complementary manner within the reaction layer: a minimum in the Fe signal and maximum Ni signal, respectively. Cobalt remained relatively constant across the reaction layer before dropping toward zero near the reaction layer/filler metal interface. The "very dark" phase in Fig. 18B corresponds to a peak of $\mathrm{Al}$ signal at the same interface. Progressing from the interface into the filler metal, $\mathrm{Fe}, \mathrm{Ni}$, and $\mathrm{Co}$ exhibited small concentration gradients that were barely greater than the sampling volume of the EPMA technique.

The reaction layer compositions were determined at the three black arrows in Fig. 21B:

- Low-Al composition: $(\mathrm{Fe}, \mathrm{Ni}, \mathrm{Co})_{75 \pm 6} \mathrm{Al}_{25 \pm 2} \approx(\mathrm{Fe}, \mathrm{Ni}$, Co) ${ }_{3} \mathrm{Al}$

- Medium-Al composition: (Fe, Ni, Co $)_{68 \pm 4} \mathrm{Al}_{32 \pm 2} \approx(\mathrm{Fe}, \mathrm{Ni}$, (o) $)_{2} \mathrm{Al}$
- High-Al composition: $(\mathrm{Fe}, \mathrm{Ni}, \mathrm{Co})_{59 \pm 10} \mathrm{Al}_{41.3 \pm 0.9} \approx(\mathrm{Fe}, \mathrm{Ni}$, Co) ${ }_{3} \mathrm{Al}_{2}$

These compositions were compared to those of reaction layers formed by the same Ag-10Al filler metal, but using brazing conditions of $965^{\circ} \mathrm{C}\left(1769^{\circ} \mathrm{F}\right)$ for $5 \mathrm{~min}$. The low-Al phase exhibited a small increase in $\mathrm{Al}$ content from $21 \pm 2$ to $25 \pm 2$ at.- $\%$. A significant change was not observed in the medium-Al composition. The high-Al phase exhibited an $\mathrm{Al}$ content of $41 \pm 1$ at.- $\%$, which was less than the $45 \pm 1$ at.- $\%$ observed after brazing at $965^{\circ} \mathrm{C}\left(1769^{\circ} \mathrm{F}\right)$ and $5 \mathrm{~min}$. Overall, the harsher process conditions altered only slightly the reaction layer compositions, despite an ample reserve of $\mathrm{Al}$ present in the filler metal. These observations further substantiate that system chemical potential controlled the reaction layer composition as opposed to simply accelerating the rate kinetics.

\section{Discussion}

A considerable amount of reaction layer data - thicknesses, microstructure, and composition measurements have been presented in this report. In addition, important findings were reported in Part 1, based on the sessile drop configuration. The objective of this section is to pull together all results to determine the root cause for the run-out phenomenon. The analyses are organized into four topical areas: visual observations, reaction layer composition, microstructure, and thickness data.

\section{Visual Observations}

Capillary forces have a significant role in run-out by the molten filler metal. First, the sessile drop samples in Part 1 did not exhibit run-out lobes. Those specimens did exhibit a sharp increase in general wetting and spreading between 2 and $5 \mathrm{wt}-\% \mathrm{Al}$ filler metal additions, which was correlated to an increased $\mathrm{Al}$ concentration in the reaction layer. Secondly, as a sessile drop, the Ag-0Al filler metal did not exhibit wetting and spreading on the Kovar ${ }^{\mathrm{TM}}$ surface. However, when placed between two Kovar ${ }^{\mathrm{TM}}$ base materials, capillary forces allowed the filler metal to flow in the clearance without the presence of a reaction layer (Fig. 3). Third, capillary flow was required to form the run-out lobes in the alumina/Kovar ${ }^{\mathrm{TM}}$ base material joints (Fig. 1). The redox reaction that takes place at the filler metal/alumina interface was shown in the Ref. 1 study to be unable to support runout by itself.

Typically, only one or, at most, two lobes are observed with run-out (Fig. 1). The analysis in Part 1 suggested that the lobe geometry resulted from a localized enhancement of wetting and spreading by the filler metal (Ref. 3). The scenario was proposed whereby the localized $\mathrm{Al}$ concentration exceeding 2-5 wt-\% in the filler metal led to a local formation of the high-Al reaction layer ( $\mathrm{Al}>30$ at.-\% ), and thus, the run-out lobe. However, the present braze joint data did not show evidence of a spatial variation of $\mathrm{Al}$ concentration across the reaction layer of each Ag-xAl filler metal. Moreover, the images in Fig. 2 show run-out took place on a broader spatial scale than is reflected by typical active braze joints (e.g., Fig. 1). 
The above analysis indicates the lobe configuration does not result from a localized increase of $\mathrm{Al}$ in the filler metal and subsequent, localized, high-Al reaction layer. Rather, the limited number of run-out lobes is a consequence of the surface tension of the molten filler metal. The increase in the atmosphere/filler metal interfacial area, which results from the initial one or two run-out lobes, reduces the driving force (chemical potential) sufficiently to mitigate the formation of any other run-out events (lobes), even in the presence of capillary flow. Those first lobes are simply a stochastic event - that is, the joint microstructure does not have a feature that causes a run-out lobe to occur at one location versus another site.

In conclusion, visual observations indicated there is a strong propensity for run-out to occur in the braze joint configuration when the overall $\mathrm{Al}$ concentration in the filler metal was greater than, or equal to, $2 \mathrm{wt}-\%$. The Ag-0Al filler metal exhibited capillary flow, but not run-out. Therefore, capillary flow is a necessary, but not sufficient, condition for run-out lobes. The reaction layer is also a necessary contributor, but it is not sufficient since run-out lobes were not observed in the sessile drop configuration (Part 1). Therefore, both capillary forces and the proper reaction layer composition are required for run-out. Lastly, the limit of run-out lobes to one, or at most two, is a surface tension effect.

\section{Reaction Layer Compositions}

The relationship between reaction layer composition and run-out was further investigated by graphing the $\mathrm{Al}$ concentration (at.-\%) of the reaction layer phase that directly contacted the molten filler metal as a function of $\mathrm{Al}$ concentration in the filler metal (wt-\%). The graph appears in Fig. 22. The closed symbols, together with the solid blue and red lines, represent the braze joint data for the brazing conditions of $965^{\circ} \mathrm{C}\left(1769^{\circ} \mathrm{F}\right), 5 \mathrm{~min}$, and $995^{\circ} \mathrm{C}\left(1823^{\circ} \mathrm{F}\right), 20 \mathrm{~min}$, respectively. The general trend has $\mathrm{Al}$ concentration in the reaction layer phase increase with increasing $\mathrm{Al}$ content in the filler metal. The less-severe brazing conditions led to higher $\mathrm{Al}$ concentrations in the reaction layer for the Ag-5Al and Ag-10Al filler metals. The same behavior was observed for the average reaction layer concentrations of the $\mathrm{Ag}-2 \mathrm{Al}$ filler metal, but the difference was not statistically significant. This somewhat counterintuitive trend is further evidence that the brazing time and temperature affect the phase compositions through the system chemical potential rather than thermally activated, rate kinetics.

A comparison was made between these results and similar findings for the sessile drop configuration. The plot in Fig. 22 also includes the same phase concentration data that was compiled from the Part 1 sessile drop study. Those results, which are represented by the open symbols and dashed lines, showed the same trend of a greater $\mathrm{Al}$ concentration in the high-Al phase for the less severe brazing conditions. In addition, the high-Al phase had considerably higher $\mathrm{Al}$ concentrations in the sessile drop geometry than it did in the joint geometry, even when run-out was very limited for the Ag-2Al filler metal. This comparison shows the reaction layer phase has a relatively large $\mathrm{Al}$ concentration range that was sensitive to the sessile drop vs. braze joint geometry.
As noted previously, a sharp increase was observed for wetting and spreading by the Ag-xAl sessile drops between 2 and 5 wt-\%. Referring to Fig. 22, the corresponding, high-Al reaction layer phase had an $\mathrm{Al}$ content that exceeded 30 at.- $\%$. In the case of the braze joint, run-out occurred when the $\mathrm{Al}$ concentration was greater than, or equal to, 25 at.-\% (Ag-2Al filler metal). This comparison shows that capillary flow (braze joint) provided the additional driving force for run-out to occur at the lower $\mathrm{Al}$ concentration in the reaction layer.

Figure 23 shows $\mathrm{Al}$ concentrations in the medium- and low-Al reaction layer phases. The medium-Al phase exhibited the same trend as that of the high-Al phase; that is, the $\mathrm{Al}$ concentration increased with $\mathrm{Al}$ content in the $\mathrm{Ag}$-xAl filler metal. However, the $\mathrm{Al}$ concentration was statistically greater for the $965^{\circ} \mathrm{C}\left(1769^{\circ} \mathrm{F}\right) 5$ min process condition only in the case of Ag-5Al. The low- $\mathrm{Al}$ phase had an $\mathrm{Al}$ concentration in the range of 20-25 at.-\%, regardless of filler metal composition or process parameters. The same trend was observed for the sessile drop samples except for a tighter $\mathrm{Al}$ concentration range of 24-26 at.-\%. Therefore, the sensitivity of reaction layer composition to the sessile drop vs. the joint configuration was significant for the high-Al phase; very limited in the medium-Al phase; and not-at-all for the low-Al phase.

In summary, run-out occurred in the joint configuration when the $\mathrm{Al}$ concentration in the filler metal was greater than, or equal to, $2 \mathrm{wt}-\%$. That concentration gave rise to an $\mathrm{Al}$ content of greater than, or equal to, 25 at.- $\%$ in the reaction layer directly contacting the (molten) filler metal. The latter concentration was lower than the "greater than 30 at.$\% \mathrm{Al}$ " benchmark for accelerated wetting and spreading behavior by the sessile drops (Ag-xAl, $2<\mathrm{x}<5 \mathrm{wt}-\%$ ). Therefore, capillary flow allowed for run-out to take place at a lower $\mathrm{Al}$ concentration in filler metal and thus, in the reaction layer. Figure 23 showed the medium-Al reaction layer composition (joint geometry) was determined primarily by the filler metal composition and to a lesser degree, by the brazing parameters. The $\mathrm{Al}$ concentration in the low-Al phase remained statistically unchanged as a function of filler metal composition and brazing parameters and was similar to that measured for the sessile drop samples.

\section{Braze Joint Microstructure}

The SEM images documented the changes that took place to the reaction layer microstructures as a function of brazing parameters and filler metal composition. Of particular interest was the occurrence of cracks. Figure 22 shows the $\mathrm{Al}$ concentration in the corresponding reaction layer. A reaction layer was absent at the $\mathrm{Kovar}^{\mathrm{TM}} / \mathrm{Ag}-0 \mathrm{Al}$ interface.Cracks were not observed in the reaction layers of any of the $\mathrm{Ag}-2 \mathrm{Al}$ samples regardless of brazing parameters. Similarly, the reaction layers belonging to the Ag-5Al filler metal did not exhibit cracks, despite significant higher Al concentrations. Lastly, the Ag-10Al filler metal generated the high-Al, reaction layer phase having $\mathrm{Al}$ contents that exceeded 40 at.- $\%$. Cracks were present in those reaction layers for all brazing process conditions.

The root-cause analysis of the cracks begins by considering that, when brazed at $995^{\circ} \mathrm{C}\left(1823^{\circ} \mathrm{F}\right)$ and $20 \mathrm{~min}$, the Ag-10Al filler metal formed a high-Al reaction layer phase with an $\mathrm{Al}$ 
concentration of 41 at.-\%. Cracks were present. Under the same brazing conditions, the Ag-5Al filler metal generated a high-Al phase having only 30 at.-\% Al. Cracks were absent. This comparison suggested a correlation existed between $\mathrm{Al}$ content in the high-Al phase and reaction layer cracks. (Recall that cracks initiate in the high-Al phase.) However, when the same comparison was then made between the Ag-5A and Ag$10 \mathrm{Al}$ filler metals after brazing at $965^{\circ} \mathrm{C}\left(1769^{\circ} \mathrm{F}\right)$ for $5 \mathrm{~min}$, the corresponding high-Al phases had similar Al concentrations of $41.3 \pm 0.7$ and $45 \pm 1$ at.- $\%$, respectively. Yet, cracks were absent in the former case and present in the latter case. The difference in $\mathrm{Al}$ contents seemed hardly sufficient to turn on or off the cracking mechanism. Therefore, the Al content of the reaction layer was not the only factor contributing to cracks. Cracks were not an intrinsic feature of reaction layers created by the Ag-10Al filler metal (see the discussion that referenced Fig. 20.).

The search for a second factor turned to the postbraze, filler metal composition. Figure 24 shows a plot of the $\mathrm{Al}$ concentration in the filler metal as a function of the nominal (or starting) Al content of the filler metal. The brazing conditions were $965^{\circ} \mathrm{C}\left(1769^{\circ} \mathrm{F}\right), 5 \mathrm{~min}$, and $995^{\circ} \mathrm{C}\left(1823^{\circ} \mathrm{F}\right), 20 \mathrm{~min}$. The error bars are only slightly larger than the symbols. The $\mathrm{Al}$ concentration increased above trace levels with the Ag-5Al filler metal after brazing at $965^{\circ} \mathrm{C}\left(1769^{\circ} \mathrm{F}\right)$ for $5 \mathrm{~min}$, where it reached $1.8 \pm 0.1 \mathrm{wt}-\%$. The $\mathrm{Al}$ concentration increased further to $4.6 \pm 0.2 \mathrm{wt}-\%$ for the $\mathrm{Ag}-10 \mathrm{Al}$ alloy. Cracks appeared in the reaction layer. The more severe brazing conditions of $995^{\circ} \mathrm{C}$ $\left(1823^{\circ} \mathrm{F}\right)$ and $20 \mathrm{~min}$ caused negligible $\mathrm{Al}$ to remain in the $\mathrm{Ag}$ $2 \mathrm{Al}$ and $\mathrm{Ag}-5 \mathrm{Al}$ filler metals. The $\mathrm{Al}$ concentration increased significantly to $7.8 \pm 0.1 \mathrm{wt}-\%$ for the Ag-10Al filler metal. Reaction layer cracks appeared in the latter case.

The second contribution was proposed to be a loss of ductility with higher, residual $\mathrm{Al}$ content in the Ag-xAl-alloys. A study by $\mathrm{G}$. Sachs showed Ag-Al alloys exhibit a more than $50 \%$ increase in hardness and $20 \%$ decrease in elongation with $\mathrm{Al}$ additions up to $5 \mathrm{wt}-\%$ (Ref. 6). As described by Jordan et al., Seftel and Sachs also reported a rapid loss of ductility when the $\mathrm{Al}$ content exceeded 5 wt-\% (Ref. 7). Those authors concluded that $\mathrm{Al}$ additions exceeding the $5.3 \mathrm{wt}-\%$ solid-solution limit formed intermetallic compound phases upon solidification that precipitation hardened the alloy. Microstructural evidence was not provided in either reference. Precipitate particles were not observed consistently throughout the Ag-10Al joint at the resolution limit of the SEM, when the Al concentration exceeded the solubility limit of $5.3 \mathrm{wt}-\%$ [7.8 $\pm 0.1 \mathrm{wt}-$ $\% ; 995^{\circ} \mathrm{C}\left(1823^{\circ} \mathrm{F}\right) ; 20 \mathrm{~min}$ ]. Nevertheless, it is reasonable to assert that reaction layer cracks resulted from a loss of ductility by the filler metal that rendered it less effective at reducing the residual stresses generated by the thermal expansion mismatch between Ag-xAl and the Kovar ${ }^{\mathrm{TM}}$ base material.

The role of the trace amounts of $\mathrm{Fe}, \mathrm{Ni}$, and $\mathrm{Co}$ in the filler metal was also considered vis-à-vis the crack behavior. The three elemental concentrations were combined as a single pseudo-constituent. Figure 25 shows a plot of the combined concentrations as a function of nominal $\mathrm{Al}$ concentration in the filler metal. The error bars are the sum of the standard deviations from each of the three elements. Although the mean values showed a slightly decreasing trend vs. filler metal concentration for the $965^{\circ} \mathrm{C}\left(1769^{\circ} \mathrm{F}\right), 5$ min process, they were unchanged, statistically. On the other hand, a maximum oc- curred at $\mathrm{Ag}-5 \mathrm{Al}$ when the brazing process was $995^{\circ} \mathrm{C}\left(1823^{\circ} \mathrm{F}\right)$ and $20 \mathrm{~min}$. Recall that the corresponding reaction layers did not exhibit cracks. The lowest concentration of $\mathrm{Fe}+\mathrm{Ni}+\mathrm{Co}$ occurred with the Ag-10Al alloy where cracking was prominent. Therefore, a correlation cannot be developed between the total concentration of $\mathrm{Fe}, \mathrm{Ni}$, and Co vs. crack development. Lastly, Fig. 25 clearly shows that the $\mathrm{Fe}+\mathrm{Ni}+\mathrm{Co}$ concentrations resulted from a complex interaction between the Kovar ${ }^{\mathrm{TM}}$ base material, the filler metal composition (Al content); and the process conditions. The $\mathrm{Fe}, \mathrm{Ni}$, and Co concentrations were not simply a function of dissolution controlled by thermally activated rate kinetics.

Particles were observed at a few isolated locations in the clearances of the Ag-10Al filler metal - Figs. 16 and 19B. Their compositions were similar to the high-Al reaction layers as was initially established in Part 1. The particle source was the spalling of a localized, accelerated growth by the reaction layer into the filler metal. The root-cause has not been identified for this mechanism.

In summary, reaction layer cracking, which was observed only with the Ag-10Al filler metal, was attributed to the latter's reduced ductility caused by the higher residual Al concentration. The elevated strength impeded the relaxation of residual stresses caused by thermal expansion mismatch between the filler metal and Kovar ${ }^{\mathrm{TM}}$ base material. Trace concentrations of $\mathrm{Fe}, \mathrm{Ni}$, and $\mathrm{Co}$ in the filler metal were not consistent with the trends observed for reaction layer cracks. The limited formation of spalled particles was not likely to have been a first-order effect.

\section{Reaction Layer Thickness}

The reaction layer thicknesses were plotted in Fig. 26 as a function of the nominal $\mathrm{Al}$ content of the filler metal. Separate traces were provided for each of the four brazing process conditions. The error bars represent \pm one standard deviation and were included only with the $965^{\circ} \mathrm{C}\left(1769^{\circ} \mathrm{F}\right), 5 \mathrm{~min}$, and $995^{\circ} \mathrm{C}$ $\left(1823^{\circ} \mathrm{F}\right), 20 \mathrm{~min}$ data. The error bars were similar for the other brazing conditions, but were omitted for clarity. Generally, reaction layer thickness increased with $\mathrm{Al}$ concentration in the Ag-xAl filler metal. However, statistically significant trends could not be discerned between the individual process conditions with the exception of the Ag-10Al alloy and the two extreme process conditions. Rather, layer thickness was controlled primarily by the nominal Al content of the filler metal.

In summary, the reaction layer thickness increased with $\mathrm{Al}$ concentration in the Ag-xAl filler metal. The thickness did not exhibit a statistically significant difference as a function of brazing process parameters with the exception of a single case. This trend implies that the layer thicknesses, like their associated compositions, were not determined solely by the thermally activated, reaction rate kinetics (brazing parameters). Rather, reaction layer thickness was controlled by the chemical potential (driving force), which in this instance, was determined primarily by the filler metal composition.

\section{Conclusions}

1. A study was performed that examined the microstructural characteristics of braze joints made between the Ko- 
var $^{\mathrm{TM}}$ base material and Ag-xAl filler metals $(\mathrm{x}=0,2,5$, and $10 \mathrm{wt}-\% \mathrm{Al})$. The brazing temperatures were $965^{\circ} \mathrm{C}\left(1769^{\circ} \mathrm{F}\right)$ and $995^{\circ} \mathrm{C}\left(1823^{\circ} \mathrm{F}\right)$ and brazing times, 5 and $20 \mathrm{~min}$. The brazing process was performed under high vacuum.

2. Run-out occurred in the presence of capillary flow (joint geometry) and $\mathrm{Al}$ concentrations in the filler metal that were greater than, or equal to, $2 \mathrm{wt}-\%$. The latter condition corresponded to an $\mathrm{Al}$ content, $\mathrm{y}$, in the interface reaction layer, $(\mathrm{Fe}$, $\mathrm{Ni}, \mathrm{Co})_{\mathrm{x}} \mathrm{Al}_{\mathrm{y}}$ that was greater than, or equal to, 25 at.-\%.

3. Reaction layer cracking, which was observed only with the Ag-10Al filler metal and all brazing conditions, was attributed to a loss of ductility by the filler metal resulting from high residual $\mathrm{Al}$ concentrations. The reduced ductility prevented the relaxation of thermal expansion mismatch stresses. Trace concentrations of $\mathrm{Fe}, \mathrm{Ni}$, and $\mathrm{Co}$ did not have a significant effect.

4. Isolated regions of the particles were observed in the Ag-10Al filler metal, which spalled into braze alloy from the high-Al reaction layer phase.

5. The reaction layer thickness increased with $\mathrm{Al}$ concentration in the Ag-xAl filler metal, but generally did not exhibit a consistent dependency on brazing process parameters. This trend indicated that layer growth was not dependent solely upon thermally activated, reaction rate kinetics. Rather, like the reaction layer compositions, the reaction layer thickness was controlled by the system chemical potential as determined primarily by the composition of the Ag-xAl filler metal and, secondarily, by the brazing process conditions.

\section{Acknowledgments}

The authors wish to thank Rebecca Wheeling for a thorough review of the manuscript. Sandia National Laboratories is a multimission laboratory managed and operated by
National Technology and Engineering Solutions of Sandia LLC, a wholly owned subsidiary of Honeywell International Inc. for the U.S. Department of Energy's National Nuclear Security Administration under contract DE-NA0003525.

\section{References}

1. Vianco, P. T., Walker, C. A., De Smet, D., Kilgo, A. C., McKenzie, B. M., Kotula, P. M., and Grant, R. L. 2015. Understanding the run-out behavior of a Ag-Cu-Zr braze alloy when used to join alumina to an Fe-Ni-Co alloy. Proc. $6^{\text {th }}$ International Brazing and Soldering Conference. Eds. R. Gourley and C. Walker, CD-ROM. Miami,

Fla.: American Welding Society.

2. $\operatorname{Kovar}^{\mathrm{TM}}$ is a registered trademark of Carpenter Technologies, Reading, $\mathrm{Pa}$.

3. Vianco, P. T., Walker, C. A., De Smet, D., Kilgo, A. C., McKenzie, B. M., and Grant, R. L. 2018. Interface reactions responsible for runout in active brazing: Part 1. Welding Journal 97(2) 35-s to 54-s.

4. Binary Alloy Phase Diagrams: Volume 1. 1986. Ed. T. Massalski. ASM International, Materials Park, Ohio, pp. 16, 25, and 48.

5. Massalski, T. ibid, pg. 3.

6. Sachs, G. 1934. Chapter 7: Verfetigung von Legierungen. Pracktische Metallkunde. Springer, Berlin, Germany. DOI: 10.1007/ 978-3-7091-5320-8

7. Jordan, L., Grenell, L., and Herschman, H. 1927. Tarnish resisting silver alloys. Technology Papers of the Bureau of Standards, No. 348. U.S. Govt. Printing Office, Washington, D.C., pp. 472, 473.
PAUL T. VIANCO (ptvianc@sandia.gov), CHARLES A. WALKER, DENNIS DE SMET, ALICE KILGO, BONNIE M. MCKENZIE, and RICHARD L. GRANT are with Sandia National Laboratories, Albuquerque, N.Mex.

\section{Authors: Submit Research Papers Online}

Peer review of research papers is now managed through an online system using Editorial Manager software. Papers can be submitted into the system directly from the Welding Journal page on the AWS website (aws.org) by clicking on "submit papers." You can also access the new site directly at editorialmanager.com/wj/. Follow the instructions to register or log in. This online system streamlines the review process, and makes it easier to submit papers and track their progress. By publishing in the Welding Journal, more than 70,000 members will receive the results of your research.

Additionally, your full paper is posted on the American Welding Society website for FREE access around the globe. There are no page charges, and articles are published in full color. By far, the most people, at the least cost, will recognize your research when you publish in the world-respected Welding Journal. 